
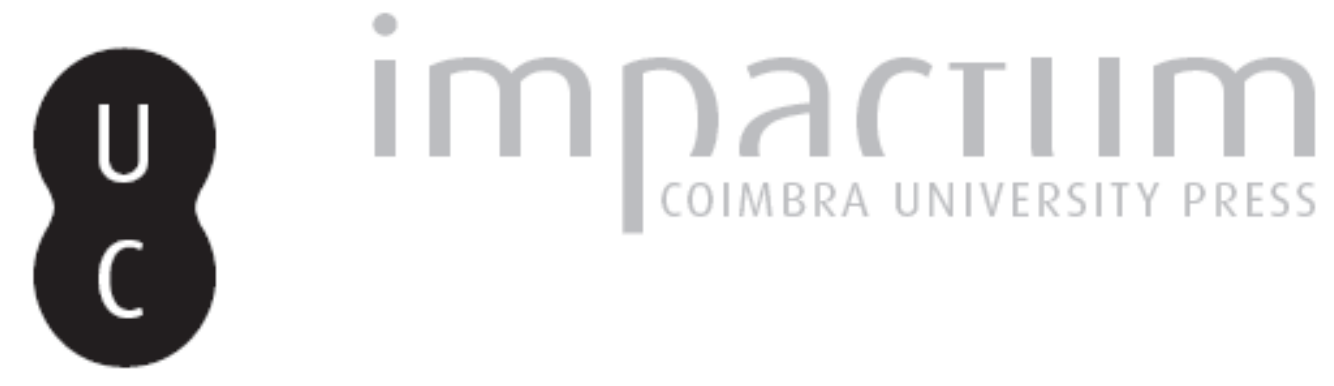

\title{
La zona minera de Tresminas (Vila Pouca de Aguiar): Aportaciones a partir de la fotografía aérea
}

\author{
Autor(es): $\quad$ Sánchez-Palencia, F. Javier
}

Publicado por: Faculdade de Letras da Universidade de Coimbra

URL persistente:

URI:http://hdl.handle.net/10316.2/39130

DOI:

DOI:http://dx.doi.org/10.14195/1647-8657_54_7

Accessed : $\quad$ 26-Apr-2023 10:29:40

A navegação consulta e descarregamento dos títulos inseridos nas Bibliotecas Digitais UC Digitalis, UC Pombalina e UC Impactum, pressupõem a aceitação plena e sem reservas dos Termos e Condições de Uso destas Bibliotecas Digitais, disponíveis em https://digitalis.uc.pt/pt-pt/termos.

Conforme exposto nos referidos Termos e Condições de Uso, o descarregamento de títulos de acesso restrito requer uma licença válida de autorização devendo o utilizador aceder ao(s) documento(s) a partir de um endereço de IP da instituição detentora da supramencionada licença.

Ao utilizador é apenas permitido o descarregamento para uso pessoal, pelo que o emprego do(s) título(s) descarregado(s) para outro fim, designadamente comercial, carece de autorização do respetivo autor ou editor da obra.

Na medida em que todas as obras da UC Digitalis se encontram protegidas pelo Código do Direito de Autor e Direitos Conexos e demais legislação aplicável, toda a cópia, parcial ou total, deste documento, nos casos em que é legalmente admitida, deverá conter ou fazer-se acompanhar por este aviso.

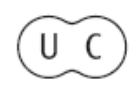


CONIMBRIGA

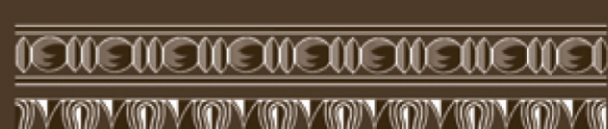

WN N N N

INSTITUTO DE ARQUEOLOGIA

VOLUME LIV • 2015

FACULDADE DE LETRAS 


\title{
F. JAVIER SÁNCHEZ-PALENCIA
}

Departameno de Arqueología y Procesos Sociales. Instituto de Historia del CSIC javier.spalencia@cchs.csic.es

LA ZONA MINERA DE TRESMINAS (VILA POUCA DE AGUIAR). APORTACIONES A PARTIR DE LA FOTOGRAFÍA AÉREA ${ }^{1}$

\author{
THE MINING AREA OF TRES MINAS (VILA POUCA DE AGUIAR). \\ CONTRIBUTIONS FROM AERIAL PHOTOGRAPHY \\ "Conimbriga" LIV (2015) p. 179-223 \\ http://dx.doi.org/10.14195/1647-8657_54_7
}

RESUMEN: Para completar la documentación de un nuevo centro de interpretación en la zona minera de Tresminas, se ha llevado a cabo una investigación basada en la fotointerpretación estereoscópica de varios vuelos aéreos (1948, 80 y 93), y los correspondientes trabajos de campo. Se ha conseguido así una documentación

${ }^{1}$ Este trabajo se inserta dentro del proyecto "Paisajes de dominación y resistencia. Procesos de apropiación y control social y territorial en el cuadrante noroccidental hispano" (PADORE) del MINECO (HAR2012-33774). Se realizó a raíz de mi participación en el nuevo centro de interpretación de Tresminas, promovido por la cámara municipal de Vila Pouca de Aguiar y ejecutado por la empresa ArqueoHoje, a cuyos responsables, Luís Filipe Gomes y Joaquim Pereira Garcia, agradezco su confianza en mí. Mi labor ha consistido en la investigación y asesoría científica del contexto geohistórico, particularmente en todo lo relacionado con la tecnología minera, en estrecha colaboración con Pedro C. Carvalho. El trabajo ha sido intenso por el escaso plazo disponible, pero creo que se han alcanzado unos resultados plenamente satisfactorios para una mejor difusión y explotación comunitaria y duradera, es decir, "sostenible" de la zona minera de Tresminas. Este trabajo y sus aportaciones forman parte de esos resultados, hasta el punto de que su proyección social ha precedido a la exposición científica.

Conimbriga, 54 (2015) 179-223 
nueva sobre varios aspectos de la minería antigua: redimensionar el tamaño de las labores, definir las acumulaciones de estériles y poner de relieve algunos elementos de la red hidráulica de abastecimiento mal conocidos, concretamente una serie de depósitos escalonados que servían para el tratamiento de molido del mineral y la evacuación del estéril. A partir de ello se han elaborado nuevas propuestas de trabajo para mejorar el conocimiento de la zona.

Palabras Clave: Minería Antigua; Arqueología del Paisaje; Noroeste de la Peninsula Ibérica; Imperio Romano

ABSTRACT: To complete the information for the implementation of a new Visit Center in the mining area of Tresminas, it has been carried out an investigation based on the stereoscopic photo-interpretation of several air flights (1948, 80 and 93), and the corresponding fieldwork. It has thus gained a new documentation on various aspects of ancient mining: resizing of the mines, defining accumulations of waste and highlight some elements of the hydraulic network, namely a series of cascade-deposits serving for the treatment of ground ore and waste evacuation. From this results new proposals to improve knowledge of the area have been produced.

Keywords: Ancient Mining; Landscape Archaeology; Northwest of the Iberian Peninsula; Roman Empire 


\section{LA ZONA MINERA DE TRESMINAS (VILA POUCA DE AGUIAR). APORTACIONES A PARTIR DE LA FOTOGRAFÍA AÉREA}

La zona minera de Tresminas es sin duda uno de los lugares claves a escala europea para poder comprender en toda su extensión la importancia que tuvo la actividad minera en el mundo antiguo y más en particular dentro del Imperio Romano. La razón primera de ello es la naturaleza y envergadura de los trabajos allí realizados durante los dos primeros siglos de nuestra Era, que supusieron la transformación a escala topográfica del terreno. La segunda es el excelente estado de conservación en que han llegado hasta nosotros casi todas las estructuras, lo que facilita la visión y comprensión de la tecnología empleada para su realización. La tercera es que, gracias a esas dimensiones y a ese buen estado de conservación, las labores antiguas de Tresminas son representativas de una actividad minera y de un proceso histórico que se extiende por todo el noroeste peninsular y que fueron claves en el desarrollo de la zona. La cuarta es que, más allá de esa representatividad, algunas de las estructuras y elementos mineros conservados poseen una notable singularidad e incluso espectacularidad. Destacan en primer lugar los aplomados frentes de explotación de las impresionantes Cortas de Covas y Ribeirinha, luego, las diversas galerías de prospección, transporte y desagüe y por último, como elementos más singulares, los numerosos morteros o molinos de pilones utilizados para el tratamiento del mineral, sin duda el referente más destacado de esta zona minera.

El mineral de oro explotado en Tresminas está en estado nativo y contiene un importante contenido de plata (de 2,7 a 4,1 g/ton según Domergue 1987 II: 537, que sigue el informe Ghitulesco de 1939 de los archivos de la Société Minière et Métallurgique de Peñarroya España). Se encuentra en partículas de tamaño muy pequeño (submicroscópico) asociadas a sulfuros metálicos en filones, lentejones o 
pequeñas venas de cuarzo (formando un stockwerk) que encajan en una roca de esquisto con diverso grado de metamorfismo ${ }^{2}$. Esa mineralización primaria está afectada por fuertes procesos de alteración genética y meteórica, de modo que la roca presenta múltiples fracturas y diaclasas, que fueron aprovechados por los mineros antiguos para extraerla más fácilmente. En último término, el tratamiento minero antiguo se basó en deshacer esas rocas y reducirlas a un tamaño finísimo para separar el oro por gravedad. La ley o contenido en oro del yacimiento de Tresminas es muy variable, estaría entre 0,4 y $14,30 \mathrm{~g} /$ ton siguiendo a Domergue (1987 II: 537: informe Ghitulesco de 1939 de los archivos de la S.M.M.P.E; esa misma ley es la que dan Pereira y MeIRELES 1998: 20, aunque no indican su procedencia). J. WAHL (1999: 68) apunta una ley de $10 \mathrm{~g} /$ ton (no indica la procedencia de esa estimación), pero sólo para el mineral, que considera en una proporción de 1:10 respecto al estéril, por lo que la ley total del material removido se situaría en $1 \mathrm{~g} /$ ton. En todo caso, como ocurre en la gran mayoría de las minas de oro del noroeste peninsular, resulta muy difícil calcular el oro obtenido en la Antigüedad. En varias ocasiones y sólo para hacer estimaciones generales, aprovechando los conocimientos del geólogo L. C. Pérez García, hemos aplicado una ley media de $0,6 \mathrm{~g} / \mathrm{m} 3$ (1,68 g/ton) para hacer cálculos de producción en todas las labores romanas sobre yacimientos filonianos del noroeste (PÉREZ-GARCÍA et alii 2000: 226, table 1; Pérez García y SÁNChez 2000: 188, cuadro 27).

\section{Antecedentes y metodología}

No es mi intención hacer un ejercicio historiográfico acerca de Tresminas, que cuenta con numerosos trabajos precedentes gracias a los cuales es una de las labores más conocidas no sólo del noroeste peninsular (Fig.1), sino de todo el mundo romano. Aparte de algunos trabajos introductorios ya históricos como los de Cardozo (1954) y Almeida (1970), prácticamente todas las monografías que se han dedicado a temas relacionados con la minería antigua han prestado espe-

${ }^{2}$ No voy a detenerme, puesto que no cuento con información novedosa al respecto, en los aspectos geológicos del yacimiento aurífero, remito a la información que aparece en la bibliografía y al catálogo de indicios del Sistema de Informação de Ocorrências e Recursos Minerais Portugueses (SIORMINP), indicio n ${ }^{\mathrm{o}} 378$.

Conimbriga, 54 (2015) 179-223 
cial atención a estas labores. Así lo han hecho, por hacer simplemente un recorrido representativo, C. Domergue (1987 II: 536-542; 2008 114-115: 122, 140-142 y 144-146), A. M. AlarCÃo (1997: 95-105) y C. MarTins (2008 Catálogo: 196-236). Más recientemente, A. Redentor (2010) ha revisado toda la epigrafía de la zona y ha aportado una nueva interpretación de su contexto histórico. A ellos remito para establecer todos los antecedentes.

En época relativamente reciente se han llevado a cabo varios trabajos de investigación en la zona, con actuaciones arqueológicas de campo de diversa índole. Esas actuaciones han sido ejecutadas por dos equipos distintos: las llevadas a cabo por el equipo de J. Wahl, iniciados desde el Instituto Arqueológico Alemán de Madrid (J. WAHL, 1988 y 1999 como hitos muy significativos de su labor) y continuados por R. Wahl-Clerici con la colaboración de varias instituciones de investigación alemanas $^{3}$, y los que se realizaron bajo la dirección de C. BATATA (2009 y 2011). Como no podía ser de otra forma, mi trabajo es deudor de esos precedentes y muy en particular de lo aportado por los dos equipos antes mencionados, que han llevado a cabo trabajos de campo en los últimos años ${ }^{4}$. Pero mi intención no es hacer una revisión de sus resultados, sino más bien contribuir con nuevas aportaciones al mejor conocimiento e interpretación de las estructuras mineras conservadas, sin renunciar por ello al debate histórico y científico cuando sea necesario.

Como en trabajos anteriores, parto de un enfoque propio de la Arqueología del Paisaje y considero por lo tanto Tresminas como un paisaje cultural, un verdadero paradigma de la interacción y transformación del medio natural por las comunidades que lo habitan. Pretendo por lo tanto que mi aproximación sea holística, pero soy consciente de que, por las circunstancias y el escaso tiempo en que se ha producido, los instrumentos manejados para poner en práctica tal enfoque no han sido todos los que deberían ser, sino que han tenido que conformarse en esencia con la visión que proporciona la fotografía aérea a través de su análisis estereoscópico y con el posterior trabajo de campo como

${ }^{3}$ Ver en la bibliografía los artículos firmados por R. WAHL-CLERICI, B. RAMMinger, M. HeLFerT Y A. WiechowsKi.

${ }^{4}$ Más en concreto, a finales de agosto de 2010 tuve ocasión de visitar Tresminas acompañado por C. MARTINS y recorrer con C. BATATA diversas zonas donde se centraba entonces su trabajo, como la Veiga de Samardã y el túnel de Pedroso, algo por lo que quiero expresar aquí mi agradecimiento.

Conimbriga, 54 (2015) 179-223 
la forma más amplia posible de acercamiento al paisaje cultural en el tiempo disponible. Eso sí, he contado con la posibilidad de manejar tres vuelos diferentes, de 1948, 1980 y 1993. Los tres han sido de gran utilidad, aunque quiero destacar el vuelo de 1948 por tres razones muy sencillas, independientemente de su menor o mayor calidad fotográfica. La primera, que transmite un medioambiente apenas modificado por otra actuación que no sea la del uso tradicional del suelo, circunstancia que obviamente es muy importante al tratarse del análisis de unas estructuras que han quedado fosilizadas en el paisaje y sólo han sido alteradas por la incuria del tiempo; se comprenderá fácilmente que intervenciones como las reforestaciones producen un ocultamiento o destrucción que anula en buena medida las ventajas que ofrece una visión en tres dimensiones del terreno. Pero también es muy importante porque ese uso tradicional del suelo debía de estar entonces en uno de sus momentos más álgidos, o sea, que casi todo el campo era aprovechado por sus habitantes, para cultivo o para otro tipo de aprovechamiento, y por lo tanto estaba bastante despejado de la maleza que rápidamente enmascara todo lo que cubre. En fin, el vuelo se realizó en época de invierno u otoño avanzado por lo que la vegetación de frondosas, como el castaño, no cuenta con hoja y no dificulta la visión del suelo.

Dado que la zona de trabajo estaba definida ya con suficiente claridad, la metodología seguida ha sido muy sencilla y puede resumirse esencialmente en tres pasos: a) análisis estereoscópico de las fotografías aéreas y fotointerpretación de las estructuras y anomalías detectadas, b) contrastación y validación o no sobre el terreno, y con la ayuda de la bibliografía y la cartografía disponibles ${ }^{5}$, de las fotointerpretaciones y c) síntesis de los dos pasos anteriores y ampliación de las fotointerpretaciones si era necesario. Al disponer de $\operatorname{los}$ vuelos ${ }^{6}$ en formato digital, he podido ampliar las zonas de estudio según ha sido necesario, aunque nunca más allá de cinco veces por encima del original.

${ }^{5}$ La cartografía y las hojas de un ortofotograma de todo el municipio de Vila Pouca de Aguiar fueron facilitadas por la cámara municipal. En relación con dicha documentación y otra obtenida también a través de la misma cámara, así como por las visitas de campo realizadas, quiero agradecer aquí la ayuda prestada tanto por Paulo Cristiano Gonçalves, como por Patricia Machado.

${ }^{6}$ Los vuelos fueron adquiridos a través del Instituto Geográfico do Exército y corresponden al vuelo SPLAL de 1948, E: 1/15.000, al vuelo de 1980, E:1/30.000 y al vuelo de 1993, E:1/22.000.

Conimbriga, 54 (2015) 179-223 
Han sido de importancia capital los trabajos de campo llevados a cabo para comprobar las fotointerpretaciones, que a la postre me han permitido hacer un reconocimiento bastante extenso de todo el conjunto minero de Tresminas. Quiero destacar en particular la identificación de las zonas de acumulación de estériles gruesos y finos, algo que generalmente se minusvalora, pero que encierra más información de la que aparentemente pueda imaginarse y que, sobre todo, implica a su vez un replanteamiento de las estructuras relacionadas con dichos estériles. También hay que destacar los reconocimientos e identificaciones realizados en la red hidráulica, para lo cual la fotografía aérea es un útil irremplazable. A lo largo de estos trabajos ha existido un problema común e insoslayable: la densa cobertura vegetal que cubre buena parte de un terreno que hace tan sólo unos decenios se hallaba casi limpio por el cultivo y el aprovechamiento tradicional del campo ${ }^{7}$.

En definitiva, como se verá a continuación, aunque el trabajo llevado a cabo ha sido muy satisfactorio y ha permitido avanzar unas aportaciones significativas sobre la minería de Tresminas, son más todavía las perspectivas de trabajo que deja abiertas, a las que me referiré en el último apartado.

\section{Las estructuras mineras de Tresminas}

Como en el resto de las numerosas cortas a cielo abierto sobre primario del cuadrante noroccidental de la Península, las estructuras mineras conocidas en Tresminas son de tres tipos: los sectores de explotación formados sobre todo por las dos grandes cortas, las estructuras de evacuación y acumulación de estériles y la red hidráulica (FIG. 2-5). A ellas hay que añadir, ocupando un paso intermedio entre las estructuras de explotación y la evacuación y acumulación del estéril, las estructuras o elementos de tratamiento del mineral: morteros o molinos de pilones tan característicos de la zona cuya función se completaría con los molinos circulares. Pero antes que nada, vamos a dedicar un pequeño

\footnotetext{
${ }^{7}$ No quiero dejar de recordar aquí la figura amable e ilustrada del profesor Carlos Alberto Ferreira de Almeida, fallecido hace ya tiempo, con el que tuve la ocasión de visitar por primera vez Três Minas (sic, como entonces se llamaba) a finales de los años 70 del pasado siglo, cuando yo realizaba mi tesis doctoral.
}

Conimbriga, 54 (2015) 179-223 
espacio a las labores de prospección, tan necesarias en cualquier actividad minera.

\subsection{El proceso de prospección}

Aunque no existe ninguna evidencia material conocida, es muy posible que ya en época prerromana se extrajese el oro en los placeres fluviales que arrastran los ríos de la zona, es decir, el Tinhela y sus afluentes. De hecho, es sabido que en la Antigüedad, tenían fama de ser auríferos todos los ríos entre el Tajo y el mar Cantábrico.

Lo más probable es que los romanos utilizasen en su beneficio el conocimiento que tenían las comunidades de la zona sobre la existencia de oro. Pero, además de ello, como describe con claridad Plinio El Viejo (HN XXXIII, 67), emprendieron una prospección sistemática para ir descubriendo los diversos yacimientos auríferos ${ }^{8}$, al igual que hicieron con el resto de los recursos explotables. Esa prospección se iniciaba en los ríos, donde se bateaban los placeres móviles para obtener el segullo o segutilo, que era el concentrado de minerales pesados que quedaba en el fondo de la batea y donde se podían distinguir las partículas de oro por su brillo. Una vez localizada la zona de donde procedían los ríos auríferos, la segunda fase de prospección consistía en extraer muestras de las superficies, para ver si contenían oro y, si así ocurría, a ese tipo de oro se le denominaba oro talutio.

Según se ha comprobado ya en algunas zonas mineras sobre primario, como la de Pino del Oro (SÁnchez-PAlencia et alii 2014: 188-192), esta segunda fase del proceso de prospección podría contrastarse fácilmente en Tresminas de forma experimental, ya que aún se pueden ver junto a todas las cortas zonas donde afloran filones potencialmente auríferos, muy alterados y disgregados por la erosión meteórica (FIG. 6) y donde se podrían obtener unas muestras que, una vez bateadas, permitirían comprobar su contenido en oro. Ese debió ser el método utilizado en época romana en una primera labor de búsqueda, la del oro talutio (aurum talutium).

${ }^{8}$ Ver en Placido y Sánchez-Palencia 2014: 23-27 una visión sintética de los métodos de prospección utilizados en los yacimientos auríferos a partir del texto mencionado de Plinio.

Conimbriga, 54 (2015) 179-223 
La prospección se seguiría produciendo según avanzaba la explotación minera, tanto mediante la comprobación de la ley del mineral beneficiado, como mediante el empleo de trincheras, pozos o galerías que servían para extraer muestras del mineral en zonas no explotadas. Es decir, puede asegurarse que todas las galerías servirían como fuente de muestreo para analizar la riqueza del mineral. No obstante existen algunas evidencias más específicas de esa práctica prospectiva. Ese es el caso de una serie de galerías existentes al final de la Galeria dos Alargamentos en la Corta de Covas. También podrían interpretarse en tal sentido los ensanches que dan nombre a esa misma galería y que difícilmente pueden entenderse como zonas de cruce de los carruajes empleados en el transporte el mineral, puesto que en el suelo de esos ensanches faltan las típicas rodadas (FIG. 7). Recientemente un trabajo ha llamado la atención sobre estos y otros trabajos de prospección situados en el entorno inmediato de las cortas, consistentes en labores de menor envergadura realizadas con la misma finalidad de evaluación del yacimiento aurífero (WAHL-CLERICI y WIECHOWSKI 2013).

\subsection{Las cortas}

Una vez localizado el yacimiento primario, el primer paso de la explotación en Tresminas habría sido la obtención del oro canalicio, es decir, el que se extraía mediante trincheras o galerías que seguían los filones con mineral localizados en superficie, empleando para ello picos, cuñas y otros instrumentos manuales, sin la intervención de la fuerza hidráulica. Este habría sido en esencia el sistema aplicado en la pequeña Corta de Lagoinhos (FIG. 8), la más oriental de todas, la de menores dimensiones y en relación con la cual no se ha encontrado hasta ahora ninguna evidencia de abastecimiento hidráulico.

Hay que suponer que ese tipo de labor mediante trincheras marcó también el inicio en las cortas de Ribeirinha y de Covas. Pero también hay que dar por sentado que los técnicos romanos comprobaron enseguida que en ellas la mineralización se encontraba diseminada en una amplia masa de roca, formando un stockwork o stockwerk. Para beneficiarlas de forma masiva y así acceder a la mineralización aurífera diseminada, se hicieron las conocidas grandes cortas a cielo abierto. En la siguiente tabla se resumen sus dimensiones máximas: 


\begin{tabular}{|l|r|r|r|r|r|}
\hline Nombre & longitud & anchura & profundidad & $\mathrm{m}^{3}$ removidos & \multicolumn{1}{|c|}{$\begin{array}{c}\text { toneladas } \\
\text { removidas* }\end{array}$} \\
\hline $\begin{array}{l}\text { Corta de } \\
\text { Lagoinhos }\end{array}$ & 170 & 8 & 10 & 3.400 & 9.520 \\
\hline $\begin{array}{l}\text { Corta de } \\
\text { Ribeirinha }\end{array}$ & 375 & 160 & 100 & 1.500 .000 & 4.200 .000 \\
\hline $\begin{array}{l}\text { Corta de } \\
\text { Covas }\end{array}$ & 430 & 140 & 90 & 1.806 .000 & 5.056 .800 \\
\hline Total & & & & $\mathbf{3 . 3 0 9 . 4 0 0}$ & $\mathbf{9 . 2 6 6 . 3 2 0}$ \\
\hline
\end{tabular}

* Para hacer este cálculo se estima una densidad media de la roca de 2,8

En esencia, el proceso de explotación en estas cortas se hacía del siguiente modo:

- Abatimiento y extracción de la roca mineralizada, de forma manual mediante picos, mazos y cuñas y con el posible uso alterno de fuego y agua para provocar cambios rápidos de temperatura que ayudasen a romper la roca.

- Una vez extraída y rota, la roca se trituraba en el mismo lugar donde había sido abatida (FIG. 9) y se hacía una selección del material, separando por un lado los fragmentos de la roca encajante de esquisto que era estéril y por otro el mineral con la ganga de cuarzo. Si era preciso, el mineral se sometía a un lavado para eliminar el material menos pesado y a una tostación para facilitar la oxidación de los sulfuros que contenía; en todo caso, también era preciso eliminar la ganga de cuarzo que no poseía mineralización aurífera. Como es lógico, no existen evidencias arqueológicas directas para documentar todo este proceso, salvo las propias acumulaciones de los estériles y gangas y su distribución a lo largo del complejo minero. En este sentido, a pesar de las reticencias de C. Domergue (1989: 94) y de que, como él indica, las ilustraciones del De Re Metallica de G. Agricola reflejan la realidad minera del siglo XVI alemán, esas imágenes pueden aproximarnos muy bien a un tipo de trabajo, como es el de la trituración o el molido del mineral, del que resulta muy difícil obtener una documentación arqueológica directa. 
En la medida en que la fuerza hidráulica es utilizada en todas las fases del proceso (extracción, lavado y evacuación) podría considerarse que en las cortas de Tresminas se explota el aurum arrugiae, pero sin embargo aquí las partículas, salvo cuando se trata de un material de superficie muy alterado, no están en estado libre, como en los yacimientos secundarios o aluvionares. Así pués, sólo en parte es oro de arrugias (Plácido y SÁnChez-Palencia 2014: 29-31).

\subsection{Las estructuras de evacuación y acumulación de estériles}

Según Plinio (NH XXXIII, 77) la evacuación de los estériles en las explotaciones sobre roca era mucho más laboriosa que en las explotaciones sobre aluvión: "Lo que en el tipo anterior se retira con inmenso trabajo, para que no ocupe los pozos, en este es evacuado por el agua". El "tipo anterior" de minas a las que se refiere el Naturalista son las hechas por el procedimiento canalicio. En el caso de Tresminas esto sólo es aplicable a la Corta de Lagoinhos, pero como acabo de indicar las cortas sobre primario tampoco son equiparables completamente al procedimiento de las arrugias, ya que no se produce una continuidad de la fuerza hidráulica entre la extracción, el lavado y la evacuación, que es lo que resalta Plinio.

Siguiendo con la anterior cuestión sobre el alcance que tuvo el uso de la fuerza hidráulica, hay que tener en cuenta que, a causa de la diversa topografía de las cortas, la evacuación del estéril y la ganga fue distinta en los primeros momentos de la explotación en las cortas de Ribeirinha y de Covas (Fig. 4, 5a y 5b). En la primera podía ser arrojado fuera de la corta a través de las salidas practicadas en el extremo noroeste del desmonte minero y por la Galeria do Pastor en el extremo sureste, de forma que una gran parte de ese material (entre las cotas 820 y 760) pudo evacuarse directamente hacia el ribeiro da Fraga que discurre inmediatamente al norte de la corta, de ahí que en las zonas altas que rodean esta corta no se vea ningún tipo de escombro. Obviamente, en esa evacuación pudo emplearse de forma masiva el agua almacenada en el depósito d-1 (Fig. 4 y 5b). Por el contrario, en Covas, explotada en su

\footnotetext{
9 "In priore genere, quae exhauriuntur inmenso labore, ne occupent puteos, in hoc rigantur."
}

Conimbriga, 54 (2015) 179-223 
totalidad desde casi una misma cota (840) y sin salidas al aire libre eso no fue posible, por lo que en las primeras fases el estéril quedaba depositado en su entorno más próximo, aunque hay que resaltar al respecto, por la relevancia minera que tiene, que se trata de un escombro en el que prácticamente sólo hay esquisto, es decir que refleja sólo la fase de descarte de la roca encajante estéril, con anterioridad a la separación de la ganga. Este dato es especialmente significativo en el caso de las acumulaciones de estériles existentes en varios puntos al sur de la Corta de Covas, entre ésta y la carretera, ya que en ellas se puede ver todo su contenido (FIG. 10), al haber sido excavadas en época moderna, seguramente para utilizarlas como relleno de carreteras o similar. En esos primeros momentos de evacuación debieron utilizarse mecanismos a base de poleas ${ }^{10}$ que ayudasen a subir en cestos o contenedores equivalentes los estériles hasta la superficie.

Según fue profundizando la labor minera, fue preciso ir excavando una serie de galerías desde el fondo de las cortas. En la Corta de Ribeirinha fueron dos: la Galeria do Buraco Seco, hacia el centro, y la Galeria dos Morcegos, por el noroeste (g-1 y g-2 en Fig. 4 y Fig. 5b), y cuatro en la Corta de Covas: la Galeria Esteves Pinto, la Galeria dos Alargamantos, la Galeria Jürgen Wahl y la Galeria do Pilar / Galería do Texugo (g-3, g-4, g-5 y g-6/g-7 en Fig. 4 y Fig. 5a). La finalidad primera de todas ellas fue servir de túneles hasta las laderas del monte para permitir la evacuación del estéril y la ganga. Vagonetas o carretas de tracción animal o humana servirían, al menos en parte, para transportar el material a lo largo de las galerías, en cuyo fondo quedaron frecuentemente grabadas sus rodadas (FIG. 11), y en todas ellas existen importantes escombreras inmediatamente junto a las bocas de salida, ninguna de tanta envergadura como la existente tras la boca de salida de la Galeria do Pilar. También tuvieron como finalidad facilitar el desagüe de los caudales utilizados en las diversas operaciones de extracción y preparado del mineral dentro de la mina, de modo que

\footnotetext{
${ }^{10}$ Recientemente y con motivo de la realización del montaje expositivo del centro de interpretación de Tresminas se extrajo una muestra de una polea de roble procedente de la Mina dos Mouros de Jales, depositada en el Museo de Vila Pouca de Aguiar, que proporcionó una datación absoluta hacia época Claudia o mediados del siglo I d.C. (Ua49927: R_Date 1953,33. 38cal BC (95,4\%) 125cal AD. Media 46cal AD. Mediana $47 \mathrm{cal} \mathrm{AD})$, lo que introduce, creo que por primera vez, una datación radiocarbónica en la minería de la zona.
}

Conimbriga, 54 (2015) 179-223 
también los canales de evacuación de agua son normales en ellas. La importancia de esta operación de desagüe en el desarrollo de la mina se pone especialmente de relieve con la construcción de la Galeria do Texugo, cuya salida tuvo que hacerse excavando el escombro previamente vertido en las laderas, casi en el fondo del valle (FIG. 12).

Si las galerías de evacuación han recibido un trato siempre destacado en Tresminas, no ocurre lo mismo con las acumulaciones de estériles que transportaron, ausentes casi por completo en la información gráfica y en la visión que hasta ahora se ha ofrecido de este conjunto minero. Especialmente llamativo es la falta de referencias a la gran acumulación de estériles finos que rellenó el valle del ribeiro da Fraga (FIG. 3 y 13), que se extienden a lo largo de $2,8 \mathrm{~km}$ de su curso y ocupan una extensión de $104.000 \mathrm{~m} 2$, que, a la espera de un estudio más preciso, podemos estimar que suponen en torno a un millón de metros cúbicos, es decir, un tercio de todo el material removido.

$\mathrm{Al}$ considerar estas acumulaciones, tenemos que volver de nuevo a la cuestión de la fuerza hidráulica, sin cuya intervención constante hubiese sido imposible arrastrar tales volúmenes de estéril. Es evidente que durante la actividad minera, a través de los canales de desagüe de sus diversas salidas o galerías, caerían continuamente sobre el valle los materiales más finos en forma de lodos, así como los estériles menos finos arrojados ladera abajo; de hecho, las laderas todavía los contienen en gran abundancia. Su acumulación en el ribeiro da Fraga podría haber generado unas "barreras" que precisaban ser removidas con un flujo de agua más o menos seguro desde la cabecera; de hecho el relleno con los estériles finaliza un poco aguas abajo de la aldea de Ribeirinha, en un fuerte meandro a la altura de la confluencia del regato do Sabugueiro, que habría actuado como barrera infranqueable para los estériles. Ese abastecimiento de agua en cabecera pudo ser proporcionado en parte de forma natural por el ribeiro da Fraga, pero en época estival y sobre todo cuando se produjeron los grandes vertidos desde la Corta de Covas, en especial a través de las galerías Jürgen Wahl y do Pilar, que caían en un sector por encima del mencionado ribeiro, el agua necesaria tuvo que provenir de la red hidráulica, lo que podría haberse hecho de forma controlada a través de los depósitos escalonados de Fragas das Covas (FIG. 17-19) a los que me refiero en los siguientes apartados.

Conimbriga, 54 (2015) 179-223 


\subsection{El tratamiento del mineral aurífero, los molinos de pilones}

El mineral seleccionado, una pequeña parte de la roca extraída en todo caso, debía transportarse hasta los lugares donde se producía su tratamiento final. Allí debía ser sometido a un tratamiento de molido, de forma que quedase reducido, como dice Plinio El Viejo ( $N H$ XXXIII, 69), al tamaño de polvo de harina: "Lo que se ha extraído, se machaca, se lava, se tuesta, se muele. A la (molienda como si fuese) harina (que sale) del mortero se la llama escude"11. El Naturalista no especifica cómo se producía el molido, pero indica que su resultado, semejante a la harina, ha pasado por un pilón o mortero. En Tresminas se conservan dos tipos de instrumentos que tienen que ver sin duda con esa fase del tratamiento: los morteros o molinos de pilones y los molinos circulares. Voy a dejar de un lado la función complementaria de los segundos, iguales en todo a los utilizados para moler el cereal y que también se ha documentado en otras muchas zonas del noroeste peninsular, y voy a centrarme sólo en los morteros o molinos de pilones.

El primer autor que llamó la atención sobre la relación de los molinos de pilones con un posible molino mecánico movido por fuerza manual, animal o hidráulica a causa de su particular erosión y pulimento interno fue Almeida (1973: 561). A propósito de un estudio de los morteros encontrados en las proximidades del Bachicón de Fresnedo (Pola de Allande) y junto a las labores de Cecos (Ibias), yo (SÁNCHEZ-PALENCia 1984-85: 356-359) puse en relación estos restos y los encontrados en otras zonas de Hispania con el mencionado pasaje de Plinio (HN XXXIII, 69), pero me incliné por su posible uso en lavaderos del tipo de los helicoidales de Laurium (Ática). Mantengo desde luego el origen grecohelenístico de la técnica e incluso la posibilidad de que las instalaciones o dispositivos donde se instalasen algunos molinos como el de Cecos o el de Fresnedo no fuesen iguales a las que hay que proponer para Tresminas, sobre todo por la diversa morfología de las cazoletas dejadas en el interior de los molinos. Más tarde, J. WAHL (1988: 230-234) puso en relación acertadamente este tipo de instrumentos mineros con las técnicas de trituración y molido que describe en su libro VIII G. Agricola (1561, VIII, 219-223, 245-248 y 253-255).

\footnotetext{
11 "Quod effosum est, tunditur, lauatur, uritur, molitur. Farinam a pila scudem uocant".
}

Conimbriga, 54 (2015) 179-223 
Hasta ahora los molinos de pilones, grandes piezas de granito de unos $80 / 90$ x 40/45 x 40/45 cm y que se utilizaban generalmente por todas sus caras, se han encontrado fundamentalmente en cuatro puntos de la zona minera de Tresminas (FIG. 2): Tresminas (f-2) y Covas (f-3) en la vertiente meridional y Ribeirinha (f-1) (FIG. 14) y área de la Galeria do Pilar (f-4) en la norte. En todas ellas están representados por una cantidad muy importante de ejemplares, aunque seguramente son más numerosos en las dos zonas de la vertiente septentrional, más cercanas a las cortas mineras. En las tres aldeas mencionadas, se sitúan en puntos donde es abundante el agua. Destaca al respecto el hecho de que no aparezca ningún ejemplar en las zonas más altas de Covas o de Tresminas. El único sitio donde no hay agua de forma natural es en el área de la Galeria do Pilar, donde, además de los ejemplares conocidos por formar el pilar que da nombre a dicha galería, aparecen numerosos restos de dichos morteros por toda la superficie inmediata a la boca de salida (FIG. 15). Es más, también he podido ver un fragmento ladera arriba, muy próximo a la boca de salida de la Galeria J. Wahl (FIG. 15). Con ello quiero resaltar que es lógico pensar que junto a ambas galerías y, sobre todo, junto a la do Pilar existiese en época romana un establecimiento o factoria de tratamiento del mineral, fundamentalmente de su molido hasta reducirlo al tamaño de la harina, como dice Plinio, para que, después, un lavado en la batea de ese polvo permitiese obtener el concentrado aurífero final. Lógicamente, también habría otros tantos establecimientos en Tresminas, Covas y Ribeirinha.

Una vez admitido el conocimiento y uso del árbol de levas en época romana y más concretamente en Tresminas (WAHL 1999: 65-66; Domergue 2008: 144-145) al modo de los dispositivos que ilustra Agricola, creo que no hay que descartar, sino todo lo contrario, su uso en húmedo, al modo como lo describe el mismo Agricola para algunas zonas mineras auríferas y argentíferas de los Alpes y los Cárpatos (FIG. 16). Hay que recordar la cercanía al agua en todas las zonas donde se han documentado los molinos de pilones en Tresminas y retomar de nuevo la interpretación de los dispositivos existentes en Fragas das Covas como depósitos escalonados (FIG. 17-19). Además de servir para la función antes mencionada de arrastre y redistribución del estéril en la gran acumulación del ribero da Fraga, se utilizaría también como fuerza motriz de los árboles de levas que movían los pilones en los dispositivos de molido de la zona de la Galeria do Pilar. 


\subsection{La red hidráulica}

Plinio (NH XXXIII, 74-78) lo decía claramente: la importancia del agua en la minería romana de oro implicaba una labor similar o de mayor coste que la extracción y tratamiento el mineral. La zona minera de Tresminas es buen testimonio de ello. En resumen, la red hidráulica hasta ahora conocida en Tresminas constaba en esencia de cuatro tipos de estructuras (Fig. 2 a $5 b$ ):

- La presas de captación o derivación de agua (equivalentes al caput aquae de los acueductos romanos). Bastaba con hacer una presa o azud para derivar el agua así elevada hacia un canal y transportarla hasta la mina. Pero en Tresminas se construyeron auténticos diques de tierra, de unos $8 \mathrm{~m}$ de altura, como los documentados en el curso del río Tinhela en los lugares de Vale das Veias, desde donde sale el canal de abastecimiento c-1, y en La Ferrería, donde arranca el canal c-3. Estos diques permitían embalsar una cantidad de agua muy importante, asegurando así mejor el abastecimiento para la mina.

- Los canales de abastecimiento, que son denominados por Plinio El Viejo canales o corrugi, nunca acueductos, ya que eran de peor factura que estos y tenían una pendiente más elevada, entre el 0,2 y el $0,4 \%$ por lo general. Conducían el agua hasta los depósitos situados junto a los frentes de las minas. El canal c-1 llegaba hasta el depósito d-1 en la Corta de Ribeirinha y tenía un trazado de unos $16,5 \mathrm{~km}$ con una pendiente entorno al $0,2 \%$. En este canal se encuentra el túnel de Pedroso (BATATA 2008: 493), de más de $200 \mathrm{~m}$, que sirve para pasar el agua del Tinhela al ribeiro de Filhagosa. El canal c-3 llega hasta el depósito d-2, al oeste de la Corta de Covas, con un trazado de unos $9,5 \mathrm{~km}$ y una pendiente entorno al $0,25 \%$. Del canal de abastecimiento c-2, desconocemos aún su origen exacto dentro de la cuenca del río Curros, afluente del Tinhela.

- Los depósitos de almacenamiento y distribución, denominados por Plinio El Viejo piscinae o stagna. Servían para almacenar el agua conducido por los canales y distribuirlo hacia la mina. Sólo conocemos con exactitud las dimensiones del depósito d-2, al oeste de Corta de Covas, que mide unos 70 x $40 \mathrm{~m}$ y podía contener unos $4.500 \mathrm{~m}^{3}$. El depósito d-1, que se identifica claramente en la foto aérea de 1948 (FIG. 5b) ha sido alterado 
notablemente por el acondicionamiento de un mirador sobre la Corta de Ribeirinha.

- Los canales de explotación o emisarios, denominados por Plinio el Viejo emissaria. Conducían el agua desde los depósitos hasta los frentes de explotación. Ese sería el caso de los restos del canal que atravesaba el poblado de la Veiga da Samardã (BATATA 2009: 430).

Lógicamente el trazado de esta red hidráulica se llevaría a cabo con los dos instrumentos topográficos ya conocidos: la dioptra, equivalente al moderno nivel, dotada de plomadas y nivel de agua para su nivelación, que servía para trazar visuales a través de dos miras, y el coróbata o chorobates, que era una tabla con mirillas de $6 \mathrm{~m}$ de longitud (20 pies romanos) y que al poseer una mayor distancia focal podía ser más precisa, como indica Vitrubio (De Arch, VIII, 5, 1-2), también llevaba nivel de agua y plomadas.

Pero, como he dejado entrever ya, una de las estructuras más singulares del conjunto minero de Tresminas es la formada por varias construcciones o aterrazamientos someros que se alinean a lo largo de la ladera en el lugar de Fragas das Covas, justo frente a la Corta de Covas (FIG. 3-5a). Fueron puestas de relieve por WaHL (1999: 66 y 68, fig. 15; AlarCão 1997: 103 y 104), que las interpretó como instalaciones de lavado del mineral aurífero. C. MarTINs (2012: 113-114) sigue esa interpretación y aduce el paralelo de una descripción e ilustración de Agricola (Martins 2012, fig. 15 = Agricola, 1561, VIII, 225-226 y fig. p. 227) que está sacada de contexto, puesto que el tratadista alemán lo que hacía era explicar el estriado, clasificación y concentrado de mineral de cobre en medio húmedo, concretamente en el famoso distrito minero de los Cárpatos de Neusohl (Banská Bystrica, actual Eslovaquia), en absoluto se refiere a un concentrado aurífero previamente molido, como sería el caso en Tresminas; e incluso se indica que este procedimiento implica a veces arrojar el mineral recuperado en la mina desde 150 pies de altura, es decir, todo lo contrario que en el caso del que ahora tratamos. BATATA (2009: 420) excavó una de esas estructuras y al interpretar sus resultados puso en duda la calificación de las mismas como lavaderos, aunque su propuesta de una "plataforma de asiento para pilares" de un posible acueducto en dirección a la Galeria do Pilar no se entiende muy bien. Se trata de dos alineaciones formadas cada una de ellas por 17 construcciones. En la fotografía aérea de 1993 
son bastante visibles (FIG. 17), particularmente la alineación más oriental (s-1 en Fig. 2 y Fig. 5a), aunque sobre el terreno no lo son tanto en la actualidad, sin duda a causa de circunstancias debidas al paso del tiempo, ya que la zona se quemó en el verano de 2010 y hay muchas zonas cubiertas aún por troncos quemados y caídos; en otras, la ceniza ha potenciado el crecimiento de una espesa cobertura vegetal.

La construcción excavada por Batata, la $8^{\text {a }}$ de arriba abajo, se ve con bastante claridad y consiste en una plataforma o aterrazamiento de 8,18 a 8,20 m de longitud (eje mayor este-oeste) y 7,18 a 7,40 m de anchura (eje menor norte-sur). De sur a norte, la composición de esa construcción es como sigue (FIG. 18, 19 y 21):

- Un bancal de lajas de esquisto, roca propia del lugar, colocadas a hueso define la plataforma, con una altura máxima de 1,10 m sobre la ladera. Esta plataforma cuenta con un pequeño refuerzo o asiento de $1 \mathrm{~m}$ de ancho y 3,05 de largo en la esquina suroeste, donde el terreno estaba ligeramente más bajo, es decir, es una especie de cimiento por ese lado.

- Retranqueado, a 1,40 - 1,50 m de ese bancal, se levanta un muro de $50-60 \mathrm{~cm}$ de ancho y una altura máxima de $42 \mathrm{~cm}$. Está hecho con piedra de esquisto trabada con argamasa de barro. No se conserva en sus extremos, ni al este ni al oeste, por donde deja unos vanos de 82 y $90 \mathrm{~cm}$ respectivamente.

- En el lado opuesto, la ladera fue rebajada y se levantó otro muro paralelo al anterior, a una distancia de 4,58-4,80 m. Tiene la misma factura y anchura media, entre 50 y $60 \mathrm{~cm}, \mathrm{y}$, al contrario que al anterior, si cubre toda la amplitud de la plataforma: $8,18 \mathrm{~m}$.

- Retomando la descripción de C. Batata, es muy posible que el espacio dejado entre ambos muros quedase cerrado por sendos muros al este y al oeste, quizás, como él dice, hechos de tapial. Esto parece lo más lógico y una cimentación visible parcialmente apoya la hipótesis.

En definitiva, si los muros de cierre por los laterales o lados menores fuesen de la misma anchura que los conservados en los lados mayores, tendríamos un espacio rectangular aterrazado de $8,19 \times 7,29$ m, que dejaría un espacio interno de 7,29 x 4,74 m aproximadamente. $\mathrm{Su}$ profundidad sería muy irregular, ya que en el interior del espacio aflora la roca hasta más de medio metro sobre el suelo en el que se asienta el muro externo (lado sur).

Conimbriga, 54 (2015) 179-223 
Como ya he indicado, de las dos series de construcciones señaladas por Wahl, sólo la más oriental, s-1, es claramente visible en la actualidad sobre el terreno, aunque de la occidental se pueden apreciar varios aterrazamientos (FIG. 17). En la oriental ha desaparecido prácticamente la construcción $6^{\mathrm{a}}$ (siempre de arriba abajo), de la que apenas se entrevé su muro de aterrazamiento sur en el lado meridional de un camino, seguro causante de la pérdida del resto. Las 17 construcciones se extienden entre las cotas de 835 y $740 \mathrm{~m}$ aproximadamente, por lo que salvan un desnivel de unos $100 \mathrm{~m}$. Es evidente que su disposición es más o menos equidistante: la primera se encuentra a unos $12,5 \mathrm{~m}$ del corte sobre la roca del canal c-2 de abastecimiento (FIG. 20) (el que llegaba originariamente hasta la Corta de Ribeirinha para abastecer el depósito d-1) y desde esa primera hasta la octava, la distancia entre las caras externas de los bancales que definen las plataformas oscila entre los 13 y los $15 \mathrm{~m}$. Si se divide el desnivel que salvan, entre cada construcción hay una media de unos $6 \mathrm{~m}$, altura que podría salvarse sin graves problemas mediante conducciones de diversos tipos, algo que obviamente queda pendiente de una investigación sobre el terreno.

De acuerdo con esos datos y teniendo en cuenta el contexto general minero dentro del que se encuentran, creo que la interpretación como lavaderos de esas construcciones no es viable. En primer lugar porque no hay estructuras arqueológicas concretas que avalen su uso como lavaderos, únicamente su más que segura conexión con el canal c-2. En segundo lugar porque no parece razonable que, de acuerdo con lo que hemos dicho antes acerca de la situación de los dispositivos de molido, el mineral tratado en las inmediaciones de la salida de la Galería do Pilar, el más cercano sin duda, tuviese que ser subido hasta $100 \mathrm{~m}$ de altura para ser lavado. En tercer lugar porque no parece necesario una batería de 17 lavaderos para realizar la operación de lavado. Me parece más razonable pensar en la posibilidad de un dispositivo para permitir bajar el agua hasta la zona donde estaban los morteros de moler o molinos de pilones, es decir, aproximadamente a la altura de la plataforma existente a la salida de la Galeria do Pilar y, de hecho, esa es la altura que alcanza aproximadamente la última construcción, la $17^{\mathrm{a}}$ (FIG. 5a).

En definitiva, la interpretación que propongo es que las dos alineaciones de Fragas das Covas se consideren depósitos escalonados que permitirían transportar agua hasta los dispositivos de molido existentes en la zona de la Galeria do Pilar, la única de las cuatro áreas para 
molido que no cuenta con un aprovisionamiento de agua bien asegurado, al hallarse en la cabecera del valle de Ribeirinha. La existencia de dos alineaciones, ambas alimentadas desde el canal c-2, permitiría que funcionasen dos dispositivos de molido a la vez. Por otra parte, no hay que olvidar una posible segunda función, perfectamente compatible con la del molido: el mencionado uso del agua desde un punto que domina todo el valle de la vertiente septentrional de la zona minera para ayudar en la labor de arrastre y evacuación de los estériles vertidos desde las cortas y las galerías de evacuación.

No conozco ningún paralelo para este tipo de depósitos escalonados. Lo más parecido sería lo que se hacía en algunos lugares del mundo romano para resolver el problema de la presión hidrostática de algunas capturas de agua demasiado elevadas en relación con su destino: se utilizaban dispositivos en cascada, abiertos como los de Cherchel (antigua Iol Caesarea o Caesarea Mauritaniae) o subterráneos, como el excelente ejemplo del tramo Recret/Grézian dentro del acueducto Craponne de Lyon, que cuenta con 15 desniveles seguidos, cada uno de 2,5 de altura y separados entre 30 y 100 m (Hodge 1992: 160-161). En Hispania también existía algún ejemplo de conducción cerrada con pozos de amortiguamiento o de pérdida de carga: el Aqua Augusta de Corduba supera en $400 \mathrm{~m}$ un desnivel de $130 \mathrm{~m}$ con una pendiente del $33 \%$ mediante 34 pozos de amortiguamiento (GONZÁLEZ TASCÓN 2002: 93-95). También pueden ponerse como paralelo, salvada la distancia de su mayor complejidad constructiva, los famosos molinos de Barbegal (Arles), movidos por dos alineaciones de 8 ruedas hidráulicas o norias cada una (Hodge 1992: 457-461) y datados hacia el segundo decenio del siglo II d.C. (LeVEAU 2007: 191).

\section{Consideraciones finales}

Retomando el orden de exposición del artículo, voy a destacar brevemente una serie de ideas o propuestas que surgen casi directamente de lo dicho a lo largo de él.

Una de las primeras cuestiones pendientes es de orden crono-cultural. Si se quiere situar de forma más precisa el inicio de las labores y se pretende evaluar el impacto, sin duda muy importante, que tuvo la minería del oro en Tresminas es preciso en primer lugar tener una idea más cabal de lo que ocurre en la zona durante la Edad del Hierro. 
Existen una serie de indicios de poblamiento, como el castro de Castelo Redondo que tan nítidamente se ve al sureste de la aldea de Ribeirinha (FIG. 3), aunque pudiera ser un asentamiento de primera época romana, como ocurrió en múltiples zonas del noroeste peninsular. Pero lo que no se ha producido es una intervención sistemática mínima que permita conocer el patrón de asentamiento prerromano en la zona, si no en la misma Tresminas, sí al menos en su entorno más inmediato. Junto a ello y para contribuir igualmente a un mejor conocimiento del inicio de la explotación en Tresminas, sería muy interesante investigar mediante arqueología experimental el potencial aurífero de las corrientes fluviales y de la zona y la posible prospección llevada a cabo en época romana para obtener el segullo y el oro talutio. Esto implicaría planificar una campaña de obtención de muestras y de bateo, que a la par serviría para conseguir una cantidad importante de partículas para analizar cualitativa y cuantitativamente las características del oro de la zona.

Dentro de ese mismo objetivo crono-cultural, parece evidente que las labores evolucionan en general de este a oeste, remontando el valle. La corta de Lagoinhos no presenta ninguna tipo de evidencia que permita relacionarla con las otras dos, aunque su desconexión de la red hidráulica hace pensar que pudo trabajarse antes que ellas. La Corta de Ribeirinha tiene que ser, al menos parcialmente anterior a la Corta de Covas, cuyos estériles se vertieron sobre el canal de abastecimiento c-2, que alimentaba al depósito d-1, situado en la cabecera de Ribeirinha, que pudo ser abastecido a partir de entonces por c-1 e incluso por un emisario procedente de d-2 (FIG. 2, 4 y $5 \mathrm{a}$ y b).

En lo que se refiere a las dimensiones y evaluación de la producción, de acuerdo con el volumen total de material removido $(9,26$ millones de toneladas) y con la posible ley media aplicable en general a los yacimientos filonianos del noroeste peninsular (1,68 g/ton), en la zona minera de Tresminas se habrían producido algo más de 15 toneladas de oro en época romana. Si se considera que el período de actividad de la mina se prolonga a lo largo de los dos primeros siglos de nuestra Era, la media sería de unas 46 mil toneladas de material removidas por año y una producción de $75 \mathrm{~kg} \mathrm{Au} / \mathrm{año}$. Para afinar mejor esa estimación, lo necesario sería hacer un buen trabajo de restitución a partir de imágenes LiDAR. De cualquier forma, a la hora de lanzar estimaciones sobre el número de habitantes que podrían existir en la zona minera, debería contrastarse ese dato con el volumen de roca removida, de forma que no exista una desproporción excesiva entre ambos 
cálculos. Otra cuestión pendiente a lo que contribuiría dicho trabajo, sería reconocer sistemáticamente la composición de las diversas acumulaciones de estériles, para poder determinar con ello los procedimientos de selección seguidos en la Antigüedad; en el caso de los estériles que rellenan el ribeiro da Fraga, sería conveniente hacer una prospección geofísica del tipo de la realizada en Las Médulas (SÁnCheZ-Palencia et alii 2000) para precisar su volumen total. Considero que el resultado final perseguido en la zona minera era la obtención del oro en forma de polvo, cuyo destino más importante sería abastecer la acuñación de la moneda de oro romana, el aureus, por lo que debía transportarse hasta las cecas del Imperio Romano, la principal de las cuales estaba en la propia Roma. Lo que parece claro es que no existen evidencias de tratamiento metalúrgico del oro en la zona, algo que tampoco era necesario. Después del molido en los morteros de pilones, bastaba con hacer un lavado de finos con la batea para obtener el concentrado aurífero final.

En lo que respecta al trazado general de la red hidráulica, pueden señalarse tres tareas pendientes muy importantes: localizar con precisión donde nace el canal c-2 dentro de la cuenca del ribeiro de Curros, revisar los trazados probables conocidos, incluyendo los depósitos escalonados de Fragas das Covas, y establecer los volúmenes de agua que podían ser captados, conducidos y embalsados en la zona minera. Para ello, sin olvidar la fotografía aérea, nuevamente sería muy importante contar con imágenes LiDAR adecuadamente tratadas y realizar sondeos en la red hidráulica. Estos últimos podrían proporcionar a la par una información paleoambiental valiosísima.

Una de las cuestiones fundamentales respecto al contexto histórico de la zona minera es aclarar su estatus jurídico y el marco organizativo en el que se situaba la zona minera de Tresminas. La denominación de "zona minera" utilizada aquí no es casual, ya que pretende huir de una definición de las labores como "distrito minero" o territorium metallorum, incluso si se consideran conjuntamente con las de Jales y Gralheira. Es algo plenamente admitido que las minas de oro del cuadrante noroeste de la Península son, no sólo propiedad estatal, sino que fueron gestionadas directamente por el estado romano (OrEJAS y Sánchez-Palencia 2002; SANChez-Palencia et alii 2006: 265-268; SASTRE et alii 2014: 35-38 como resúmenes del estado de la cuestión) y eso es algo que ya ha sido argumentado suficientemente y no hace mucho por REDENTOR (2010: 122-125) a propósito de Tresminas y es 
la idea que se ha transmitido de la mano de Pedro Carvalho en el nuevo centro de interpretación inaugurado en 2015.

Una última cuestión puesta en tela de juicio a raíz de las intervenciones de J. Wahl es la interpretación de las estructuras existentes en el Alto do Cimo dos Lagos, pequeña elevación situada inmediatamente al sur y entre las dos grandes cortas mineras. Creo que el primero en hacer referencia a este recinto "de formato oblongo" como un posible "aquartelamiento" o asentamiento con carácter militar fue AlmeIDA (1973, 558), aunque con múltiples reservas y destacando la ausencia de materiales en superficie que ayudasen a identificarlo mejor. Desde su primer trabajo sistemático J. WAHL $(1988,237-238)$ se mostró más favorable a considerarle de forma claramente elíptica y a identificarlo como un pequeño anfiteatro. Ante la evidencia de que los restos se aproximaban más a la forma oblonga o rectangular alargada con el lado occidental en semicírculo, Batata exploró la posibilidad de que se tratase de un circo (BATATA 2009: 419) y llegó a realizar una excavación para ver si aparecía la barrera central, con resultado negativo, pero sí documento unos muros en ambos lados del recinto, el norte y el sur. Más tarde, se llevaron a cabo unos sondeos geofísicos con georadar cuyas conclusiones, también con reservas, volvieron a plantear como lo más posible la propuesta de un pequeño anfiteatro, apoyándose en los paralelos en zonas mineras británicas ya adelantados por Wahl (MARTINs et alii 2011). Lo sorprendente de esta última propuesta es que se presentan en ella dos formas alternativas para el recinto, la elíptica y la rectangular con un lado en semicírculo, todo ello a pesar de que los sondeos geofísicos mostraron que no existía ningún tipo de cierre por el oriente y de la notable diferencia entre una y otra forma (MARTINs et alii 2011, FIG. 5).

Hay que resaltar en primer lugar que la planta del recinto no es elíptica, sino que se trata, según se ve con claridad sobre el terreno y en la foto aérea de 1948 (Fig. 4) - y en todas las demás también - de un trazado en U, con el lado abierto hacia al este, por donde no se aprecia ningún resto de construcción. Las estructuras documentadas por Batata son muy someras y no iban acompañadas de materiales arqueológicos que facilitasen su datación e interpretación. Por otro lado, la superficie interior no presenta precisamente el aspecto que debería poseer una arena de juegos, no está uniformemente nivelada y ofrece un perfil convexo, máxime si se considera que los muros documentados estarían al descubierto; y todo ello no puede atribuirse a la erosión, puesto 
que es la cima del monte y no ha estado en cultivo al menos desde 1948. En fin, recientemente se han encontrado en ese lugar tres denarios de plata, dos de las cuales, hoy expuestas en el nuevo centro de interpretación, son fechables en época republicana; ambos están acuñados en Roma, uno es de L. Calpurnius Piso Frugi, del 90 a.C., y el otro de P. Crepusius, del 82 a.C. Ello nos lleva a compararlas con el tesorillo de denarios, entre ellos 36 republicanos aunque su datación post quem sea el 14-2 a.C., encontrado en la zona minera de Penamacor, en las proximidades de la Mina da Presa, que en un trabajo anterior (SANCHEZ-PALENCIA 2014: 126-130) pusimos en relación con el campamento existente junto a la misma mina y que fue destruido por las estructuras y red hidráulica mineras (anterior por lo tanto parcialmente a la mina). Según hemos propuesto recientemente acerca de ese caso y de otras zonas del noroeste peninsular (SÁNCHEZ-PALENCIA y CURRÁs 2015), el recinto del Alto do Cimo dos Lagos podría estar entonces relacionado con una primera presencia romana, quizás militar, en la zona, que habría desempeñado una labor técnica y administrativa en la puesta en marcha de toda la zona minera.

\section{BIBLIOGRAFÍA}

Agricola, Georgius (1561) - De Re Metallica Libri XII, Basilea (edición facsímil, con traducción y notas del ejemplar conservado en la Biblioteca de El Escorial. Madrid. Círculo Científico 2004).

Alarcão, A. M. (con la colaboración expresa de J. Wahl) (1997) - Aspectos da mineração romana no território portugués. In Alarcão, A. M. (coord.), Portugal Romano: a exploração dos recursos naturais. Lisboa: Museu Nacional de Arqueologia, p. 95-135.

Almeida, F. (1970) - Minas de ouro na Gallaecia portuguesa. In Legio VII Gemina (Coloquio Internacional con ocasión del XIX centenario de León, 16-21 de septiembre de 1968). León: Diputación Provincial, p. 287-301.

Almeida, C. A. Ferreira de (1970) - Aspectos da mineração romana de ouro en Jales e Trêsminas (Tras-os-Montes). XII Congreso Nacional de Arqueología, Jaén 1971. Zaragoza (1973), p. 553-562.

BAtatA, Carlos (2009) - Resultados das escavações arqueológicas de 2007 e 2008 realizadas no complexo mineiro de Três Minas e Jales. Congresso Transfronteiriço de Arqueologia (Montalegre, Outubro de 2008). Chaves. Grupo Cultural Aquae Flaviae, (Revista Aquae Flaviae 41), p. 417-431.

Batata, Carlos (2011) - Novos dados sobre o complexo mineiro romano de Trêsminas e Jales. Actas del V Congreso Internacional sobre minería y metalurgia históricas

Conimbriga, 54 (2015) 179-223 
en el Suroeste europeo (León 2008). Madrid. SEDPGYM, p. 481-490.

Batata, Carlos, Borges, N., Correia, H., Sousa, A. (2008) - Carta arqueológica do concelho de Vila Pouca de Aguiar. Vila Pouca de Aguiar: Câmara Municipal, Ozecarus.

CARDozo, Mário (1954) - A propósito da lavra do ouro na província de Trás-os-Montes durante a época romana. Revista de Guimarães 64 (1-2), p. 113-141.

Domergue, Claude (1987) - Catalogue des mines et fonderies antiques de la Péninsule Ibérique. Madrid. Diffusion de Boccard (Publications de la Casa de Velazquez Serie Archeologie, fasc. VIII).

Domergue, Claude (1989) - Le technique minière Antique et le De Re Metallica d'Agricola. In Minería y Metalurgia en las antiguas civilizaciones mediterráneas y europeas. Madrid. Ministerio de Cultura, p. 76-95.

Domergue, Claude (1990) - Les mines de la Péninsule Ibérique dans l'Antiquité romaine (Collection de l'École Française de Rome, 127). Roma. École Française de Rome.

Domergue, Claude (2008) - Les mines antiques. La production des métaux aux époques grecque et romaine. Paris. Eds. Picard.

Gonzalez TASCón, Ignacio (2002) - La ingeniería civil romana. Artifex, Ingeniería romana en España. Madrid. MECyD, p. 34-176.

Hodge, A. Trevor (1992) - Roman Aqueducts \& Water Supply. Londres: Duckworth.

Lemos, Francisco Sande, Martins, Carla M. B. (2008) - Civitates e exploração aurífera romana no Noroeste da Península Ibérica. Actas del V Congreso Internacional sobre minería y metalurgia históricas en el Suroeste europeo (León 2008). Madrid: SEDPGYM, p. 481-490.

LeveAu, Ph. (2007) - Les moulins de Barbegal. 1986-2006. In Brun, J.-P e Fiches, J.-L. (eds.), Énergie hydrauliques et machines élévatrices d'eau dans l'Antiquité. Naples. Centre Jean Bérard, p. 185-199.

MARTIns, Carla M. B. (2008) - A exploração mineira romana e a metalurgia do ouro em Portugal. Braga. Instituto de Ciências Sociais. Universidade do Minho.

Martins, Carla M. B. (2010) - Aspectos económicos, sociais e Políticos no Alto Trás-os-Montes ocidental em época romana. In Martins, Carla, M. B. (coord.), Mineração e povoamento na Antiguidade no Alto Trás-os-Montes Ocidental. Porto. CITCEM, p. 6-15.

Martins, Carla M. B. (2012) - Hidráulica mineira na época romana. In Manuela Martins, M., Freitas, I. V., Val Valdivieso, Ma I. (coords.), Caminhos de Água. Paisagens e usos na longa duração. Braga. CITCEM, p. 105-122.

Martins, Carla M. B., Carvalho, J., Almeida, F., Cavalheiro, A. (2011) - Aplicação do geo-radar no reconhecimento de uma estrutura no complexo mineiro de Três Minas, Vila Pouca de Aguiar, Vila Real. In Povoamento e Exploração dos Recursos Mineiros na Europa Atlântica Ocidental. Braga, p. 521-533.

Orejas, Almudena, SÁnchez-Palencia, F. Javier (2002) - Mines, Territorial Organization, and Social Structure in Roman Iberia: Carthago Noua and the Peninsular North-West. American Journal of Archaeology 106, p. 581-599.

Conimbriga, 54 (2015) 179-223 
Orejas, Almudena, SASTRE, Inés (2000) - El poblamiento romano en la ZAM y la diferenciación funcional. In F. JAVIER SÁNCHEZ-PALENCIA (ed.), Las Médulas (León). Un paisaje cultural en la Asturia Augustana. León. Instituto Leonés de Cultura, p. 253-283.

Parente, J. (1980) - Subsídios inéditos para a história de Três Minas. Actas do Seminário de Arqueologia do Noroeste Peninsular (Guimarães, 1979). Guimarães. Sociedade Martins Sarmento 3, p. 131-140.

Pereira, Eurico, Meireles, Carlos (1998) - Metais Preciosos em Portugal. Situação da Investigação Geológica e Mineira. Estudos, Notas e Trabalhos do Serviço de Fomento Mineiro 40, p. 3-34.

Pérez-García, L. C., Sánchez-Palencia, F. J., Torres-Ruiz, J. (2000) - Tertiary and Quaternary alluvial gold deposits of Northwest Spain and Roman mining (NW of Duero and Bierzo Basins). Journal of Geochemical Exploration 71, p. 225-240.

Plácido, Domingo, SánChez-Palencia, F. Javier (2014) - La explicaión de la minería de oro romana hispana en la Historia Natural de Plinio El Viejo, párrafos 66 a 78 del libro XXXIII. In Sánchez-Palencia, F. J. (ed.), Minería en zonas interfronterizas de Castilla y León y Portugal (Asturia y NE de Lusitania). Junta de Castilla y León. Valladolid, p. 17-34.

Ramminger, Britta, Helfert, Markus, Wahl-Clerici, Regula (2011) - Non-invasive archaeological research in the Roman gold mining district of Três Minas and Gralheira (Vila Pouca de Aguiar, northern Portugal). ICEUBI (International Conference on Engineering UBI), p. 1-9.

ReDentor, Armando (2010) - Aproximação a um esboço social da área mineira romana da serra da Padrela (Tresminas e Campo de Jales). In Martins, Carla, M. B. (coord.), Mineração e povoamento na Antiguidade no Alto Trás-os-Montes Ocidental. Porto. CITCEM, p. 121-162.

SÁnchez-Palencia, F.-Javier (1984-85) - Los "morteros" de Fresnedo (Allende) y Cecos (Ibias) y los lavaderos de oro romanos en el NO. de la Península Ibérica. Zephyrus 37-38, p. 349-359.

SÁnchez-Palencia, F. Javier (ed.) (2000) - Las Médulas (León). Un paisaje cultural en la Asturia Augustana. León. Instituto Leonés de Cultura.

Sánchez-Palencia, F. Javier (2014) - La zona minera de Penamacor-Meimoa (Castelo Branco). In Sánchez-Palencia, F. J. (ed.), Minería en zonas interfronterizas de Castilla y León y Portugal (Asturia y NE de Lusitania). Junta de Castilla y León. Valladolid, p. 103-134.

Sánchez-Palencia, F.-Javier, Currás Refojos, Brais (2015) - Campamentos romanos en zonas mineras del cuadrante noroeste de la Península Ibérica. In CAMINO Mayor, J., Peralta Labrador, E. J., Torres-Martínez, J. F. (cords.), Las Guerras Astur-Cántabras. Gijón. KRK eds., p. 173-183.

Sánchez-Palencia, F.-Javier, Pérez García, Luis C., Orejas, Almudena (2000) Geomorphology and Archaeology in the Las Médulas Archaeological Zone (ZAM) (León, Spain). Evaluation of wastes and gold production. In Vermeulen, 
F. e De DAPPER, M. (eds.), Geoarcheology of Landscapes of Classical Antiquity. Leiden. Babesch, p. 167-177.

SÁnchez-Palencia, F. Javier, Romero, Damián, Beltrán, Alejandro, Pecharromán, Juan Luis, Currás, Brais (2014) - La minería romana de Pino del Oro y su entorno inmediato (Salamanca). In Sánchez-Palencia, F. J. (ed.), Minería en zonas interfronterizas de Castilla y León y Portugal (Asturia y NE de Lusitania). Valladolid. Junta de Castilla y León, p. 181-216.

Sánchez-Palencia, F.-J., Orejas, A., Sastre, I., Pérez, L. C. (2006) - Las zonas mineras romanas del noroeste peninsular: Infraestructura y organización del territorio, Nuevos elementos de Ingeniería Romana. Valladolid. Junta de Castilla y León, p. 265-285.

SASTRE, Inés, Orejas, Almudena (2000) - Las aristocracias locales y la administración de las minas. In Sánchez-Palencia, F. Javier (ed.), Las Médulas (León). Un paisaje cultural en la Asturia Augustana. León. Instituto Leonés de Cultura, p. 284-306.

Sastre, Inés, Beltrán, Alejandro, Alonso, Fernando (2014) - La epigrafía de las zonas mineras de Asturia Augustana. In SÁnchez-Palencia, F. J. (ed.), Minería en zonas interfronterizas de Castilla y León y Portugal (Asturia y NE de Lusitania). Junta de Castilla y León. Valladolid, p. 34-62.

SAStre, Inés, Sánchez-Palencia, F. Javier (2002) - La red hidráulica de las minas de oro hispanas: aspectos jurídicos, administrativos y políticos. Archivo Español de Arqueología 75, p. 215-233.

WAHL, Jürgen (1988) - Três Minas: Vorbericht über die archäologischen Untersuchungen im Bereich des römischen Goldbergwerks 1986/1987. Madrider Mittellungen 29, p. 221-244.

WAHL, Jürgen (19939 - Três Minas. Vorbericht über die archäologischen Ausgrabungen im Bereich des römischen Goldbergwerks 1986/87. In STEUER, Heiko e ZimMERMANN, Ulrich (eds.), Montanarchäologie in Europa (Berichte zum Internationalen Kolloquium Frühe Erzgewinnung und Verhüttung in Europa in Freiburg im Breisgau vom 4.-7. Okt. 1990). Sigmaringen. Thorbecke, p. 123-152.

WAHL, Jürgen (1999) - Aspectos tecnológicos da indústria mineira e metalúrgica romana de Três Minas e Campo de Jales (concelho de Vila Pouca de Aguiar). Actas do Seminário Museologia e Arqueologia mineiras (1998). Lisboa. Museu do IGeM, p. 57-68.

WAHL, Jürgen (2003) - Zur Wasserversorgung des römischen Goldbergbaues von Três Minas und Campo de Jales (Vila Pouca de Aguiar, Trás-os-Montes, Portugal). In Stöllner, Thomas, Körlin, Gabrielle, Steffens, Gero, Cierny, Jan (eds.), Man and Mining - Mensch und Bergbau (Studies in honour of Gerd Weisgerber on occasion of his 65th birthday). Bochum. Deutches-Bergbau Museum, p. 495-502.

WAHL-Clerici, Regula (2008) - Untersuchungen zum Abbaufortschritt in der Corta de Covas (Tagebau A) im römischen Goldbergwerksbezirk von Três Minas (conc. Vila Pouca de Aguiar, Portugal). In Gorges, J. G., Nogales Basarrate, T. (ed.),

Conimbriga, 54 (2015) 179-223 
Naissance de la Lusitanie romaine (Ier av. - Ier ap. J.-C.). VIIe Table ronde internationale sur la Lusitanie romaine (Toulouse 8-9 novembre 2007). Toulouse/ Mérida 2010), p. 437-458.

Wahl-Clerici, Regula (2011) - Três Minas. Quelques remarques a propos du pilier dans la "Galeria do Pilar". In Actas del V Congreso Internacional sobre minería y metalurgia históricas n el Suroeste europeo (León 2008). Madrid. SEDPGYM, p. 471-480.

WAHL-Clerici, Regula, Wiechowski, Annemarie (2013) - Untersuchungen zur Antiken Prospektion von Erzlagerstätten mit Bergbaulichen beispielen aus dem Römischen Goldbergwerksdistrikt von Três Minas, Gralheira und Campo de Jales in NordPortugal, Madrider Mitteilungen 54, p. 299-326.

Conimbriga, 54 (2015) 179-223 


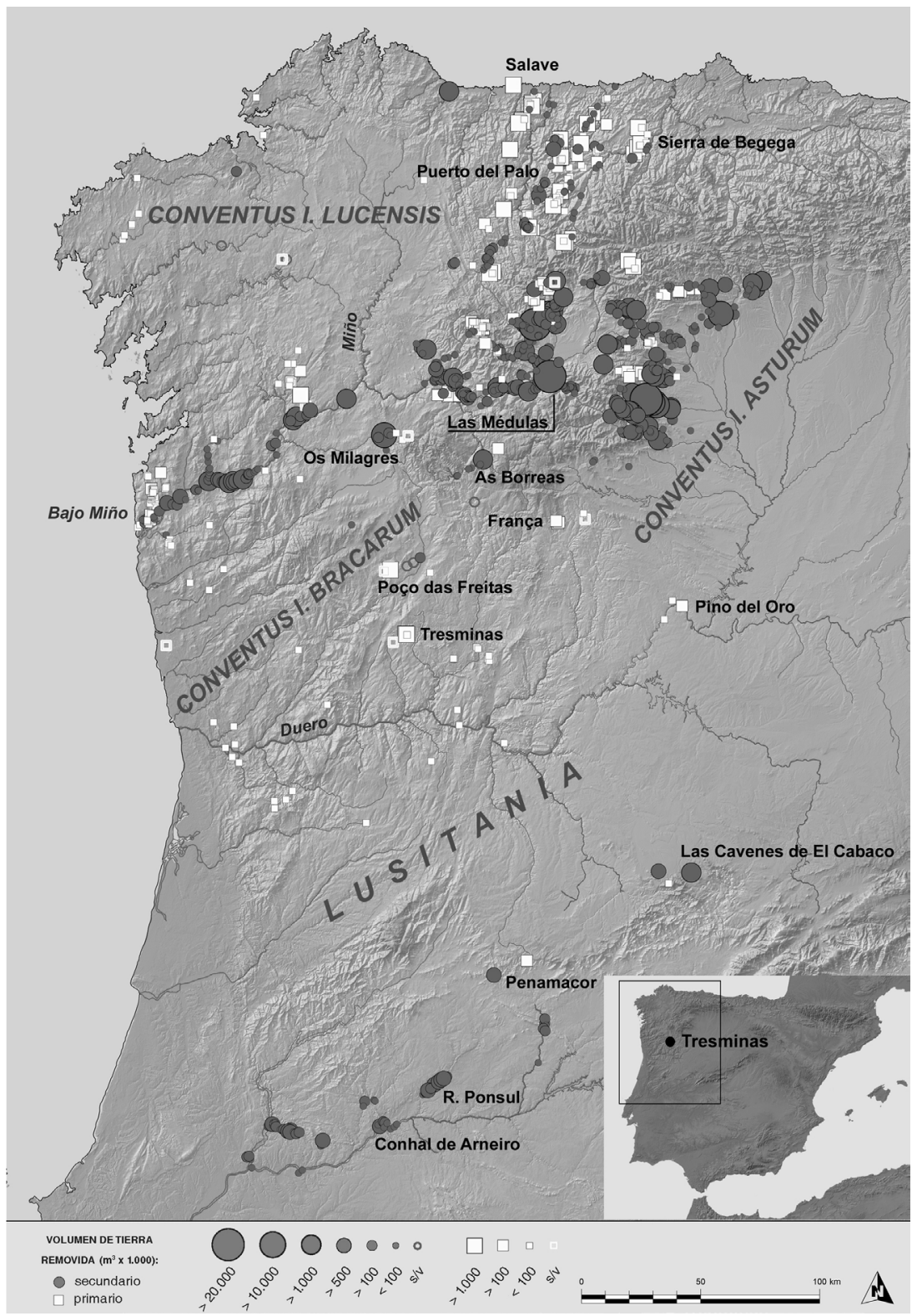

Fig. 1 - Mapa de situación de Tresminas en el contexto de la minería de oro romana del cuadrante noroeste de la Península Ibérica, con indicación del tamaño $y$ de las labores más importantes (JSP y Brais Currás). 

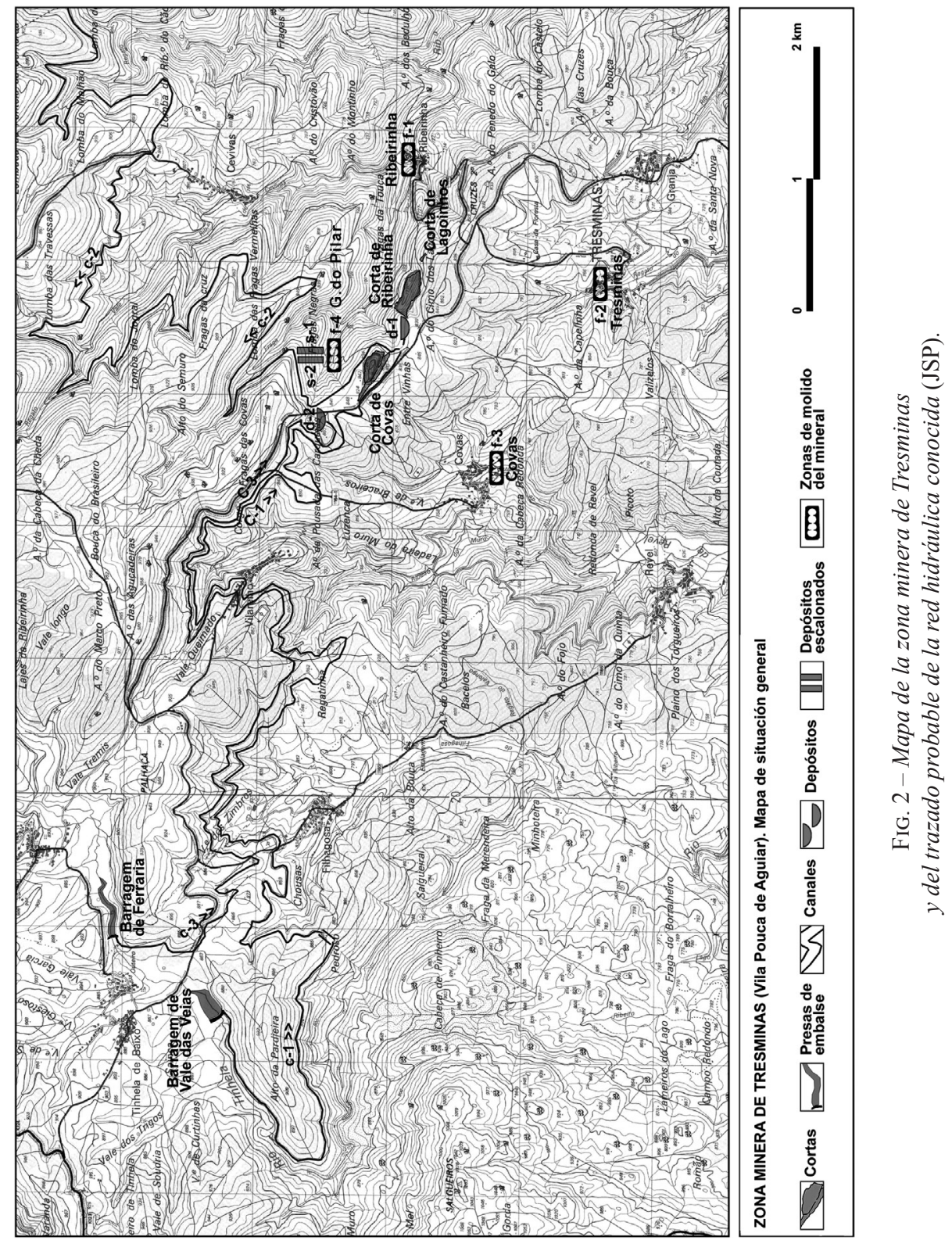

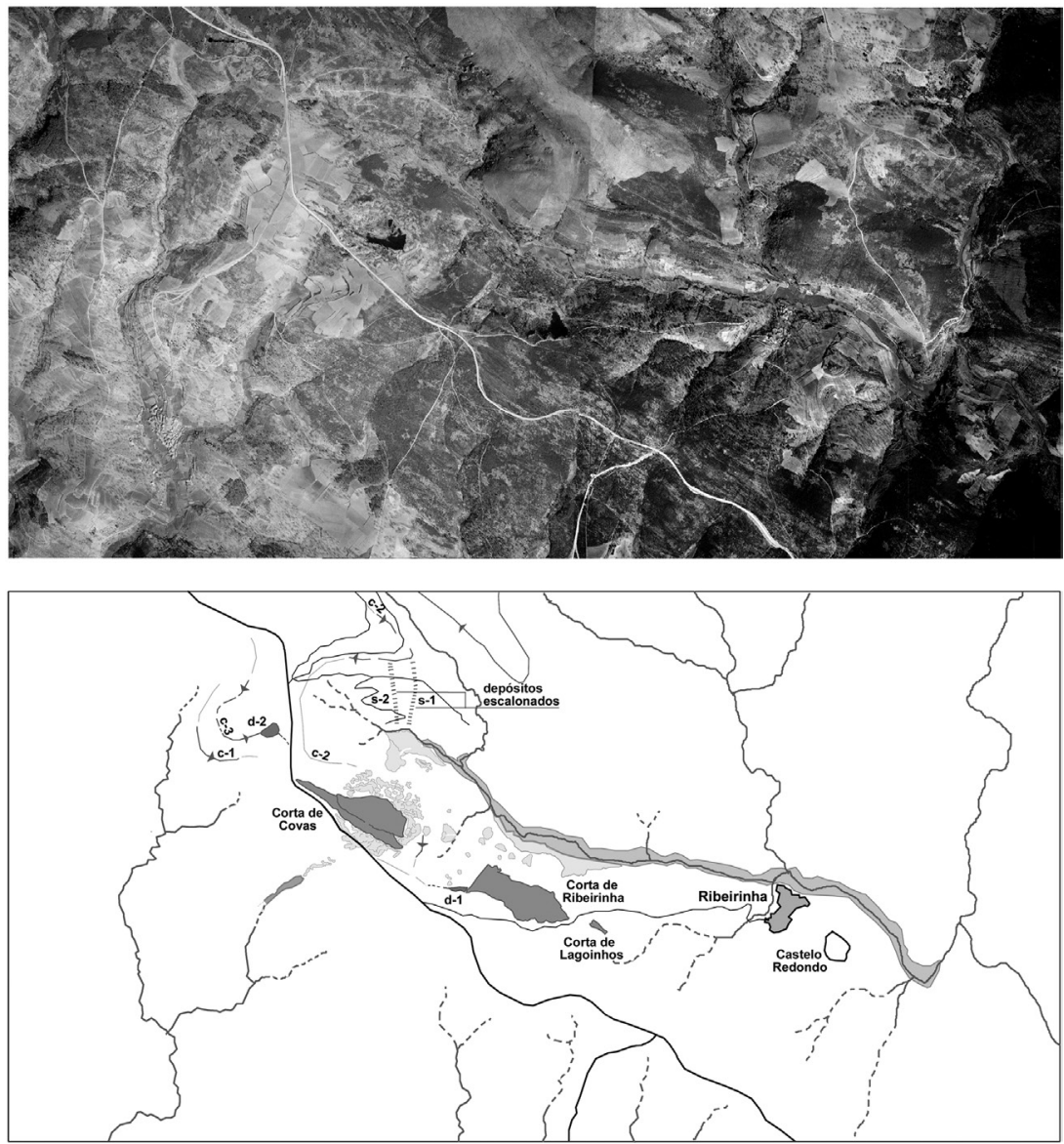

$1000 \quad 2000 \mathrm{~m}$ (aprox.)

ZONA MINERA DE TRES MINAS (Vila Pouca de Aguiar). Fotointerpretación del vuelo de 1948 (SPLAL). General de la ZoMinTres

\begin{tabular}{lll}
\hline Cortas & Red hidráulica $\quad \square$ Estériles gruesos \\
(relleno de valles)
\end{tabular}

FIG. 3 - Fotointerpretación de la zona minera de Tresminas a partir del vuelo de 1948 (JSP). 

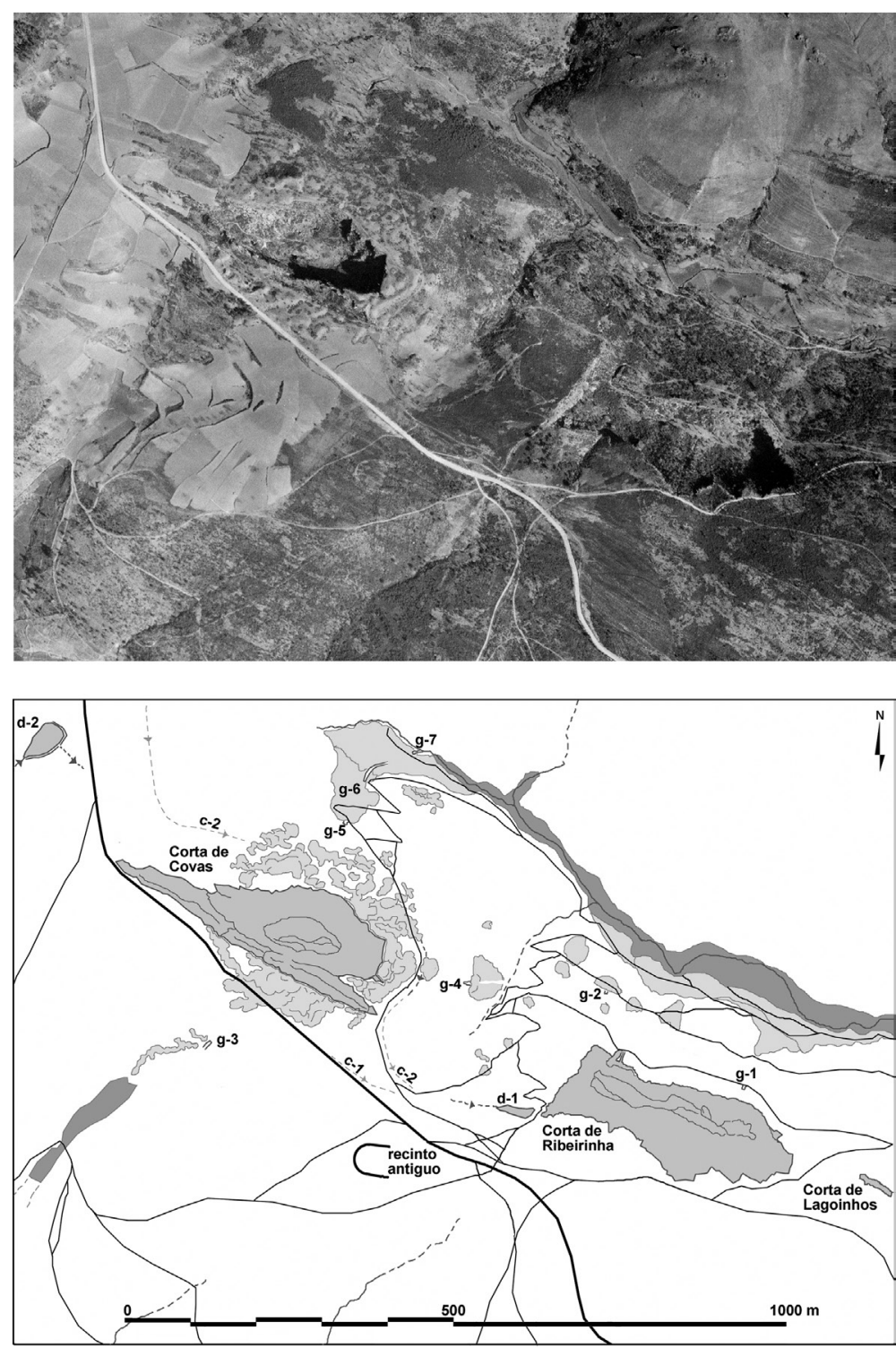

ZONA MINERA DE TRES MINAS (Vila Pouca de Aguiar). Fotointerpretación del vuelo de 1948 (SPLAL). Sector central

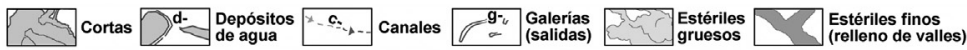

FIG. 4 - Fotointerpretación del sector principal de la zona minera de Tresminas a partir del vuelo de 1948 (JSP). 


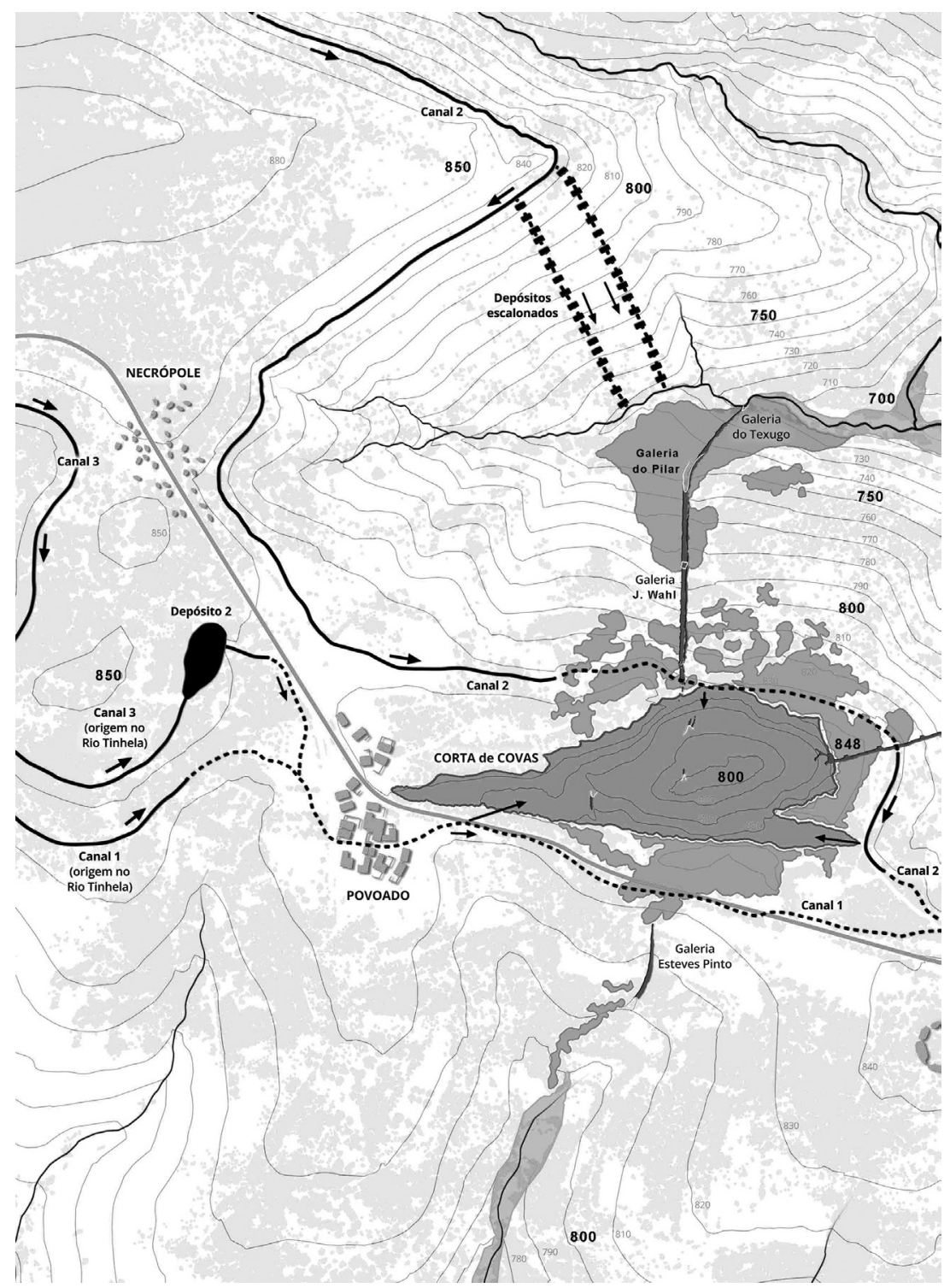

Fig. 5a - Mapa del sector principal de la zona minera de Tresminas, zona $\mathrm{W}$ (dibujo: Nuno Farinha a partir de información previa y fig. 3 y 4 para el Centro de Interpretación de Tresminas coordinado por Arqueohoje). 


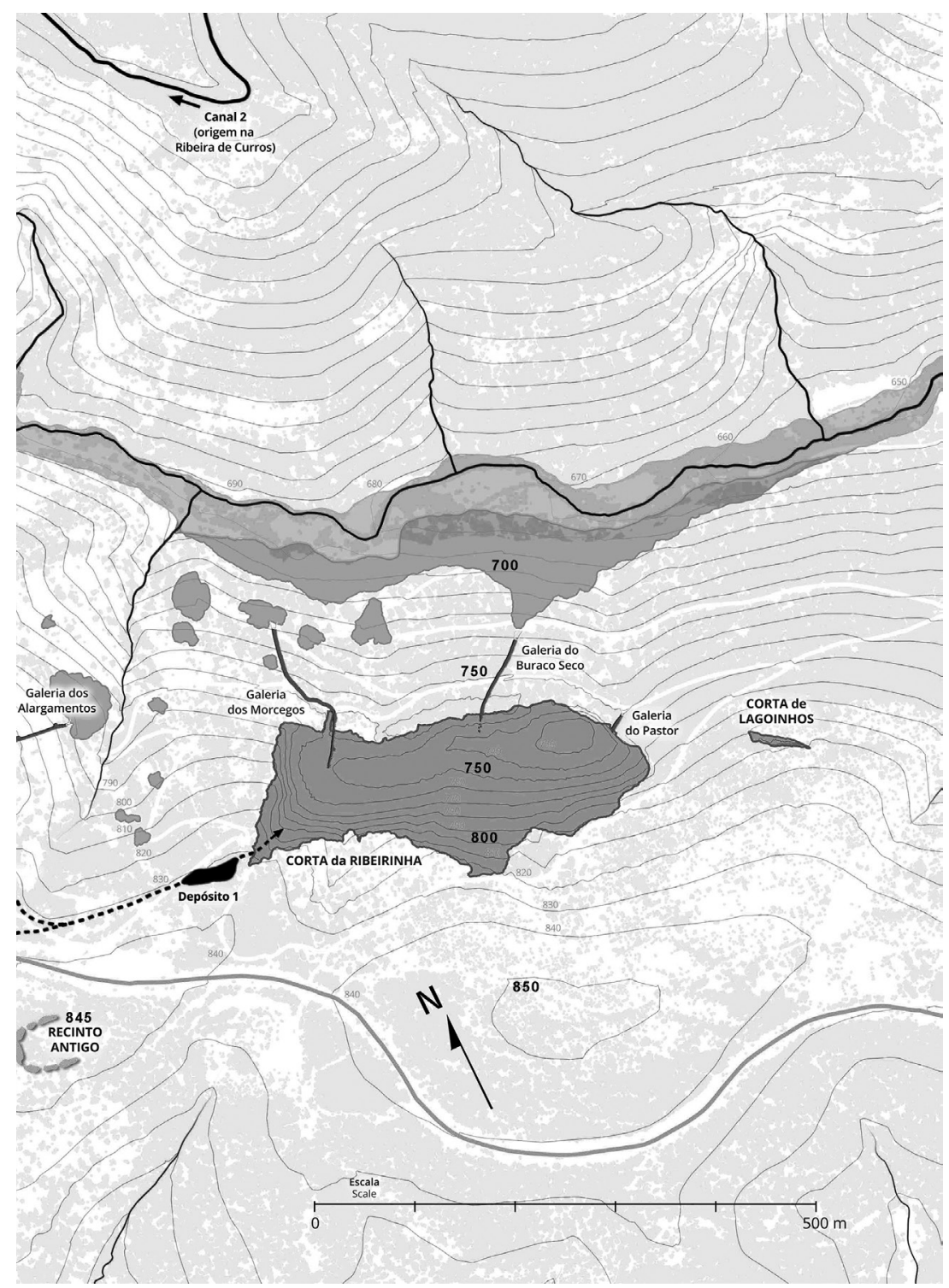

FIG. 5b - Mapa del sector principal de la zona minera de Tresminas, zona E (dibujo: Nuno Farinha a partir de información previa y fig. 3 y 4 para el Centro de Interpretación de Tresminas coordinado por Arqueohoje). 


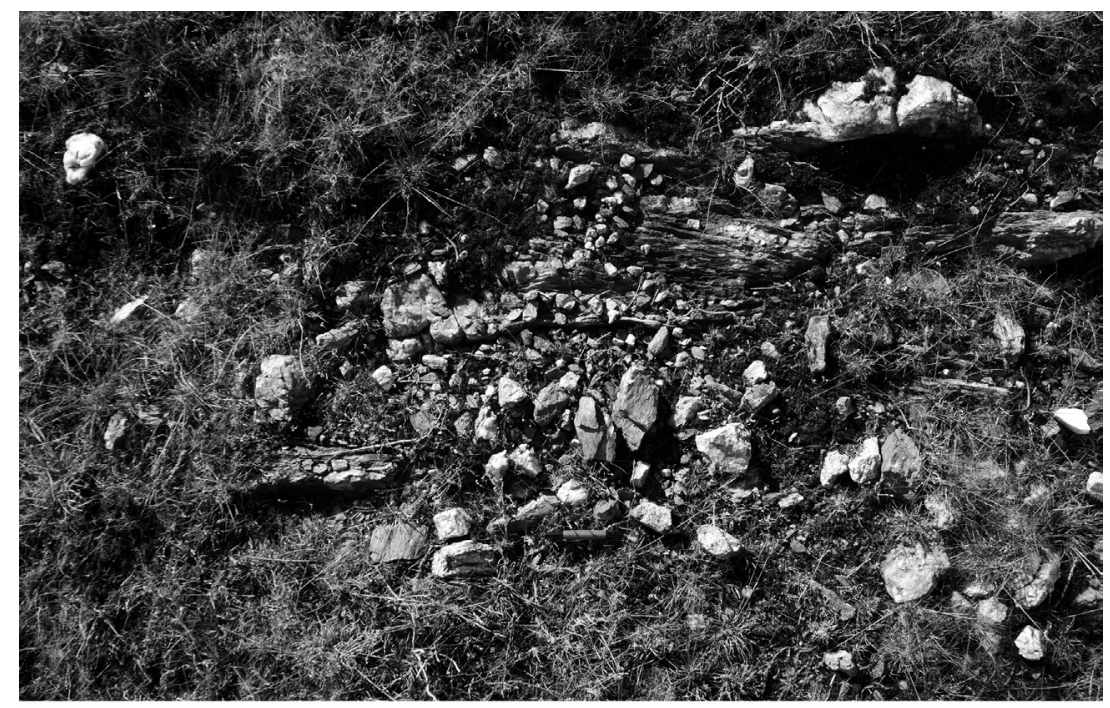

FIG. 6 - Filón alterado y disgregado al sur de la Corta de Ribeirinha (Foto: JSP).

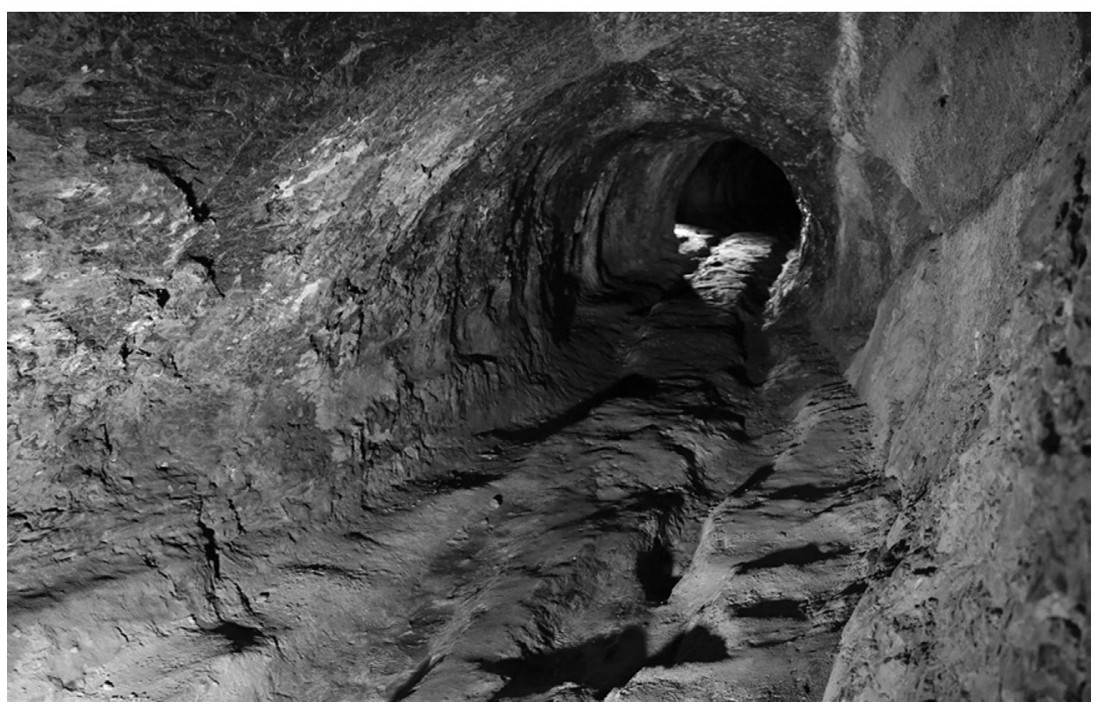

FIG. 7 - Galeria dos Alargamentos, con las típicas rodadas dejadas por los carruajes que transportaban el mineral y los estériles (Fото: Nuno Farinha). 


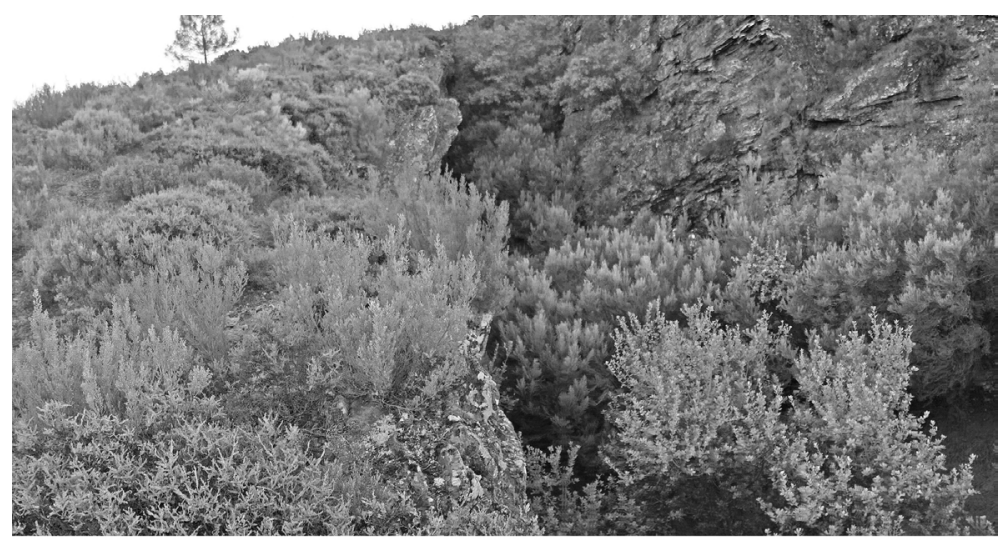

FIG. 8 - Corta de Lagoinhos, vista desde el oeste (Foto: JSP).

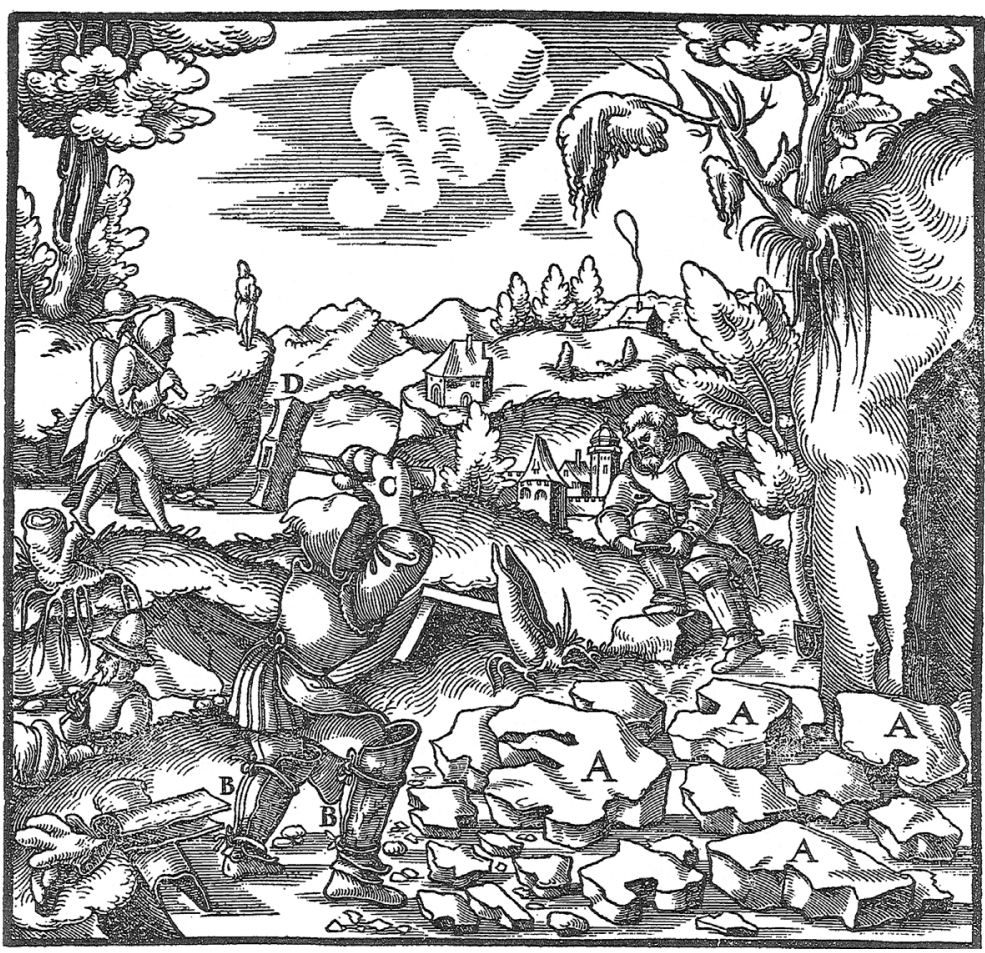

FIG. 9 - G. Agricola, De Re Metallica, 1561, libro VIII, ilustración de un modo de triturar el minera a pie de mina en la región de Goslar: A, mineral;

$B$, protecciones de corcho para las piernas; $C$, guantes; $D$, mazo de hierro 


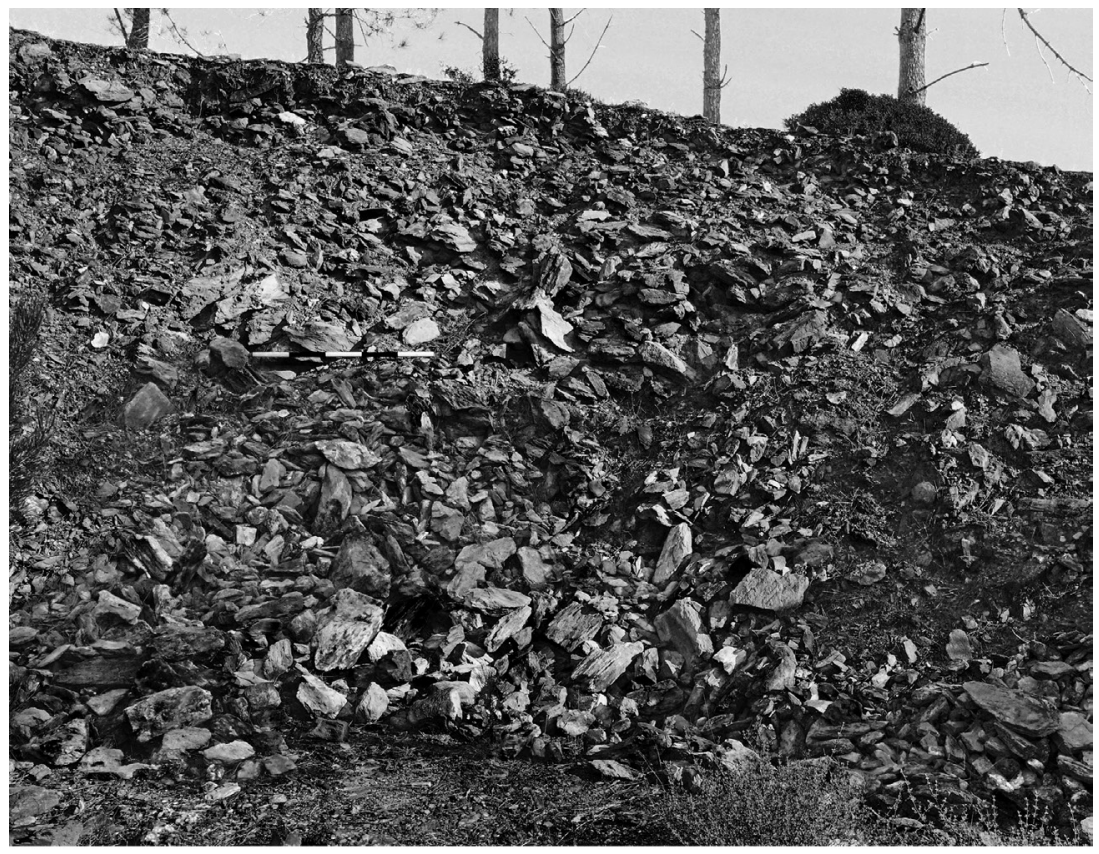

FIG. 10 - Corte realizado en época reciente en una de la acumulaciones de estériles de esquisto situadas al sur de la Corta de Covas (Foto: JSP).

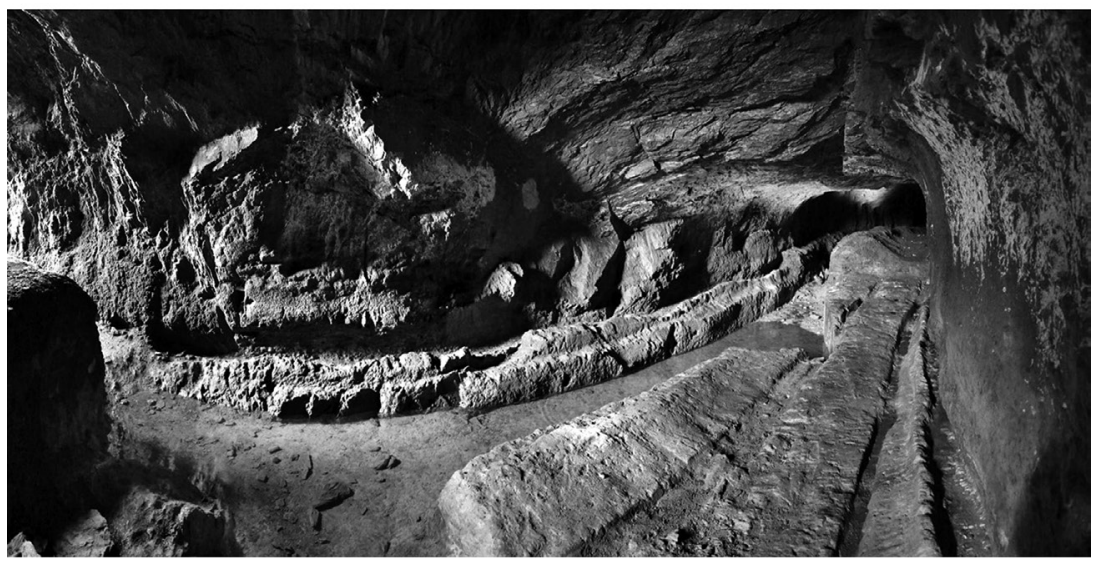

FIG. 11 - Galeria do Pilar, boca de salida, con restos de las rodadas dejadas por los carruajes que transportaban el mineral y el estéril y el canal de desagüe (Fото: Nuno Farinha). 

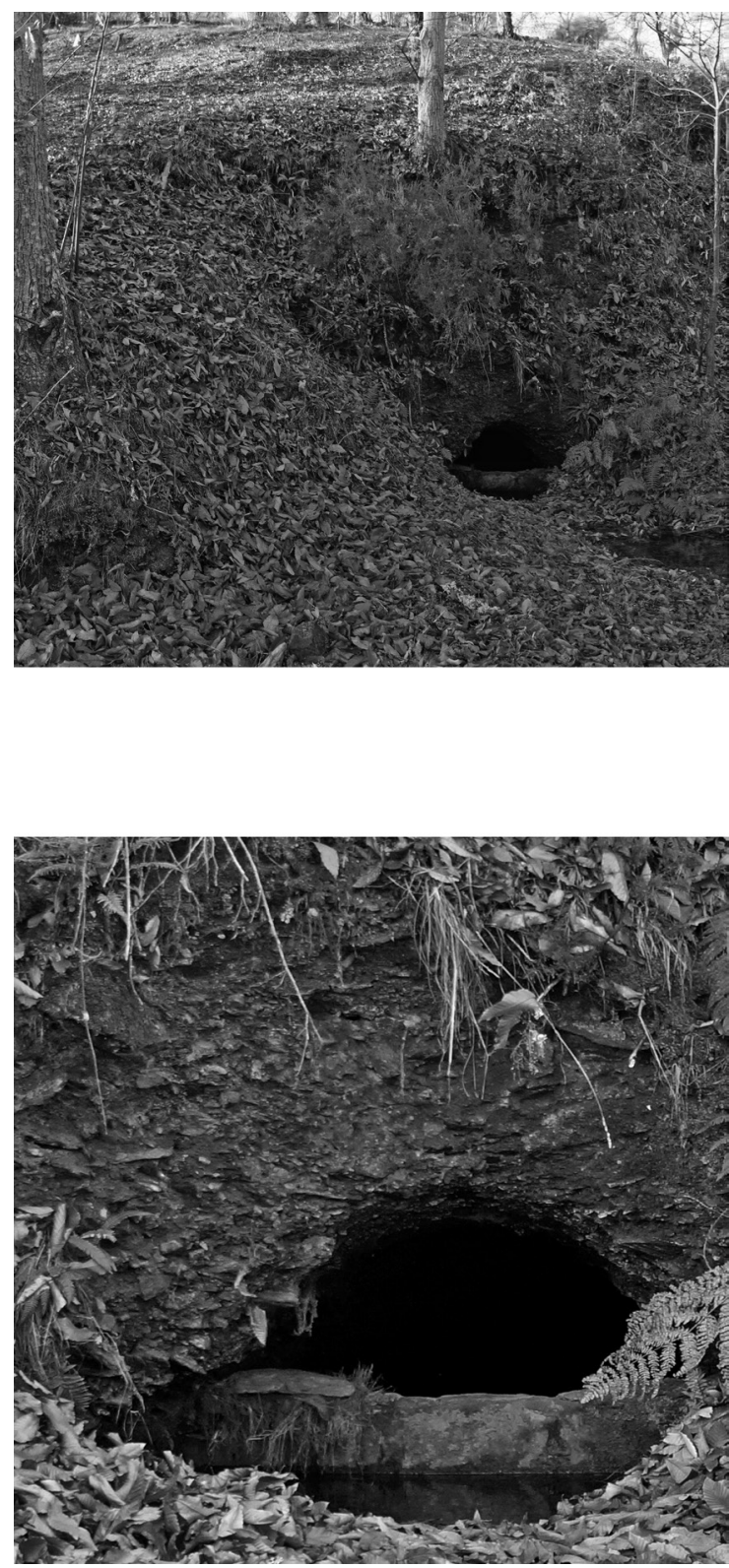

FIg.12 - Galeria do Texugo, boca de salida practicada en los estériles procedentes de la Galeria do Pilar y detalle de la misma donde se aprecia la composición de esos estériles (Fото: JSP). 


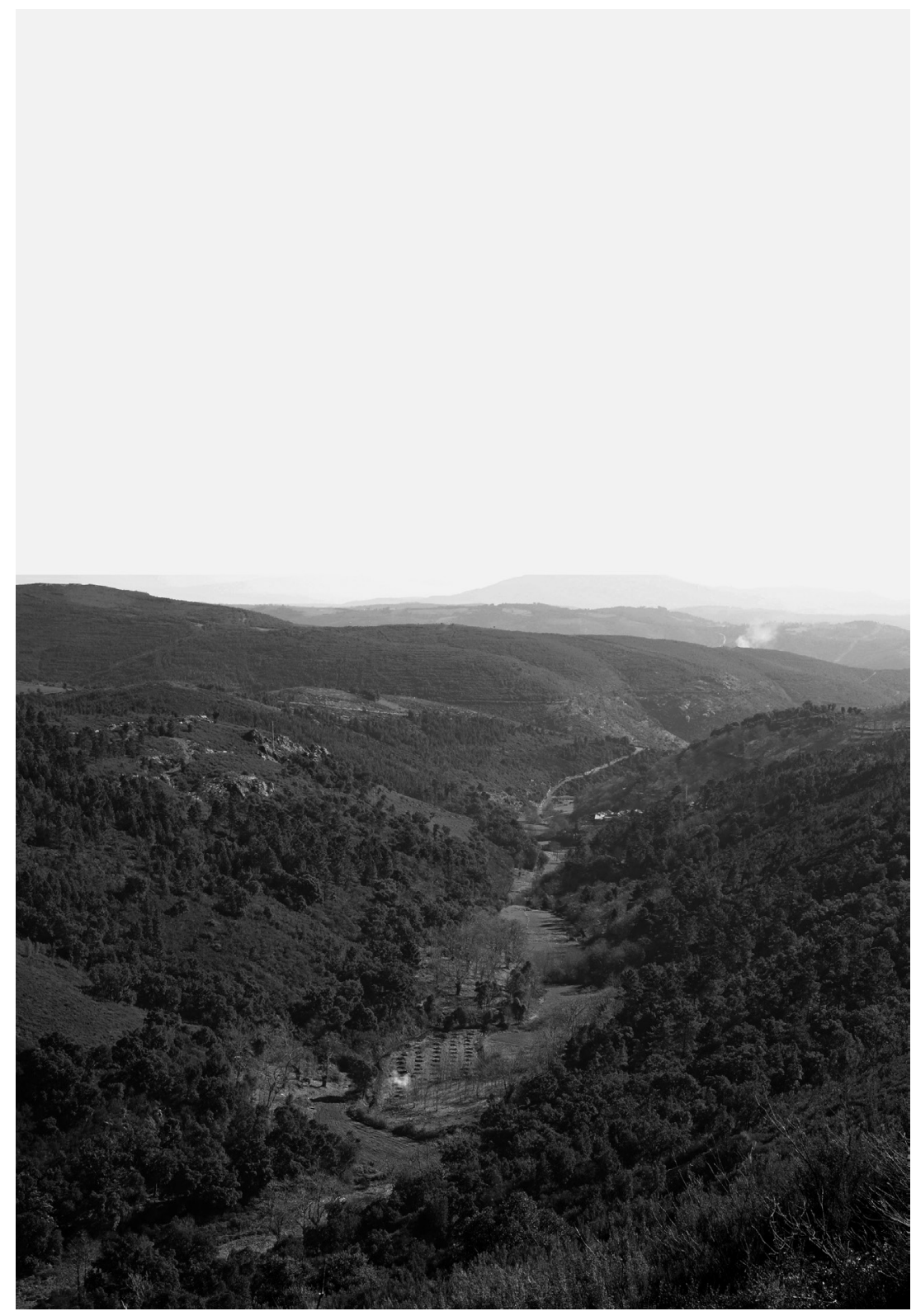

Fig. 13 - Panorámica desde el oeste del Ribeiro da Fraga, aguas arriba de Ribeirinha. El relleno aplanado del valle, hoy cultivado, está formado por los estériles romanos de las cortas de Covas y Ribeirinha (Fото: JSP). 

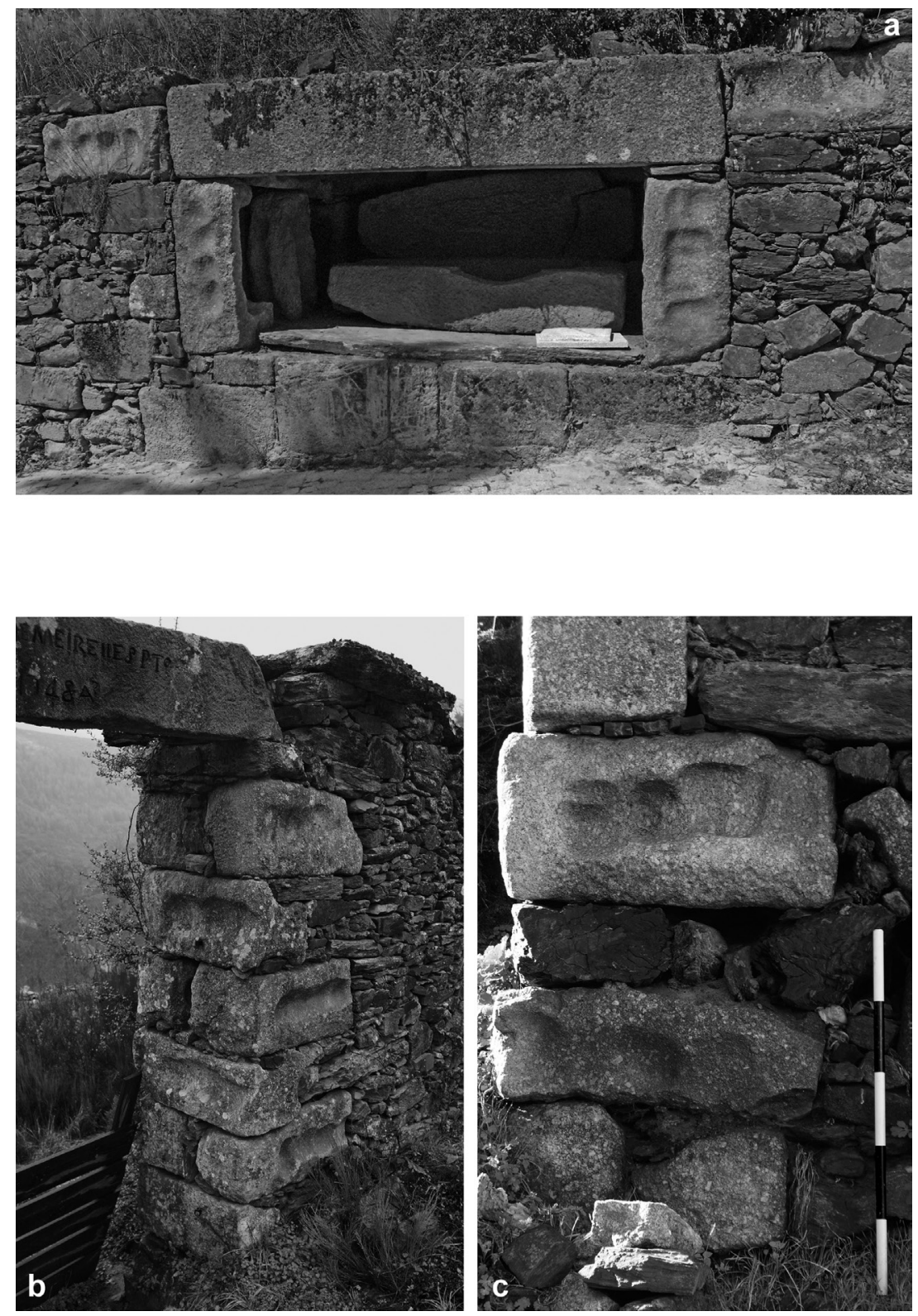

FIG. 14 - Morteros o molinos de pilones de la zona minera de Tresminas: a) sepultura monumental junto a la iglesia de S. Miguel en Tresminas; b) jamba derecha de la entrada a la casa de los Meirelles en la aldea de Ribeirinha; c) esquina de una casa de la aldea de Covas (Fotos: JSP). 

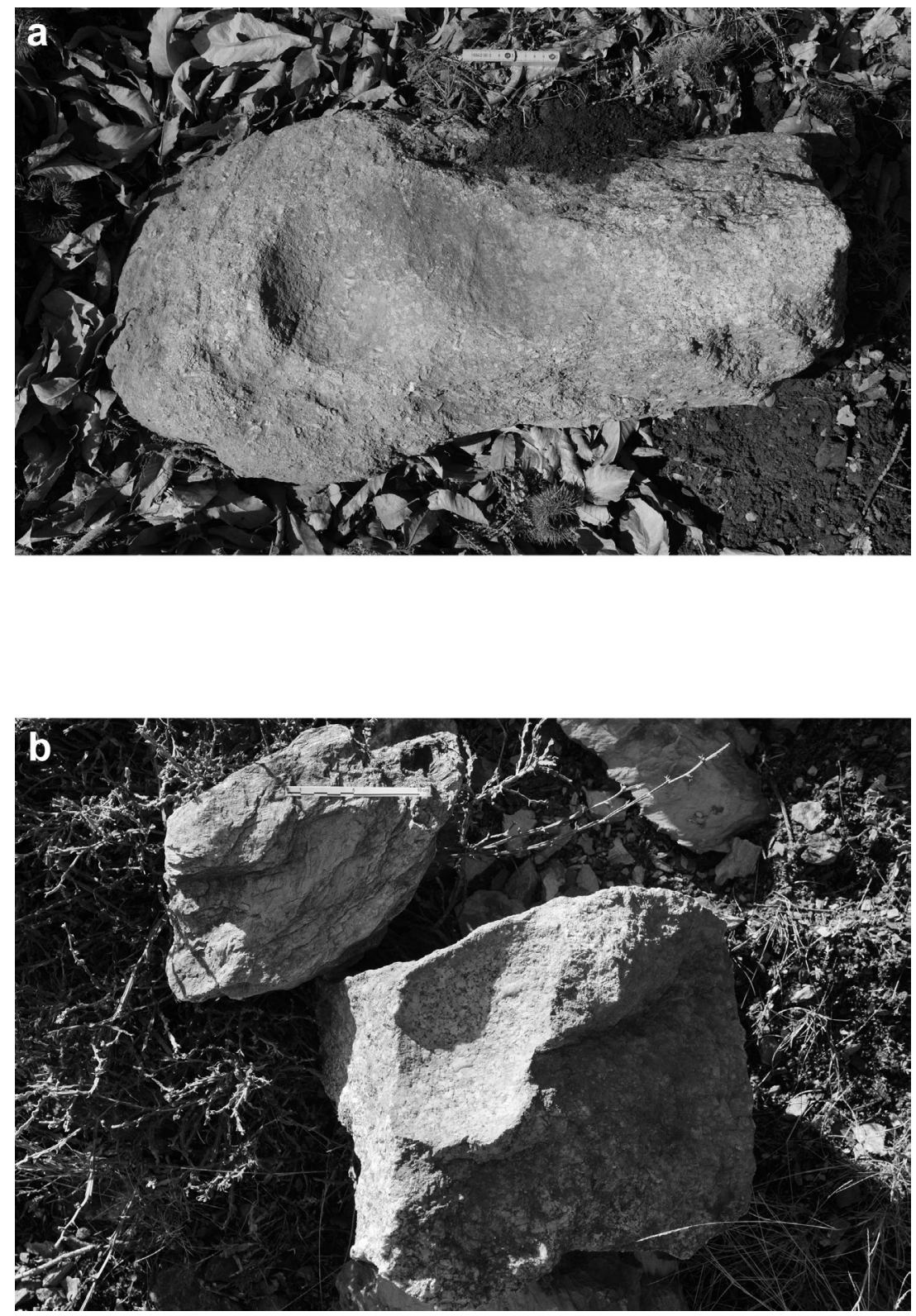

FIG. 15 - Morteros o molinos de pilones en las inmediaciones

de la boca de salida de la Galeria do Pilar y entre los estériles gruesos cercanos a la boca de salida de la Galeria Jürgen Wahl (Foтоs: JSP). 


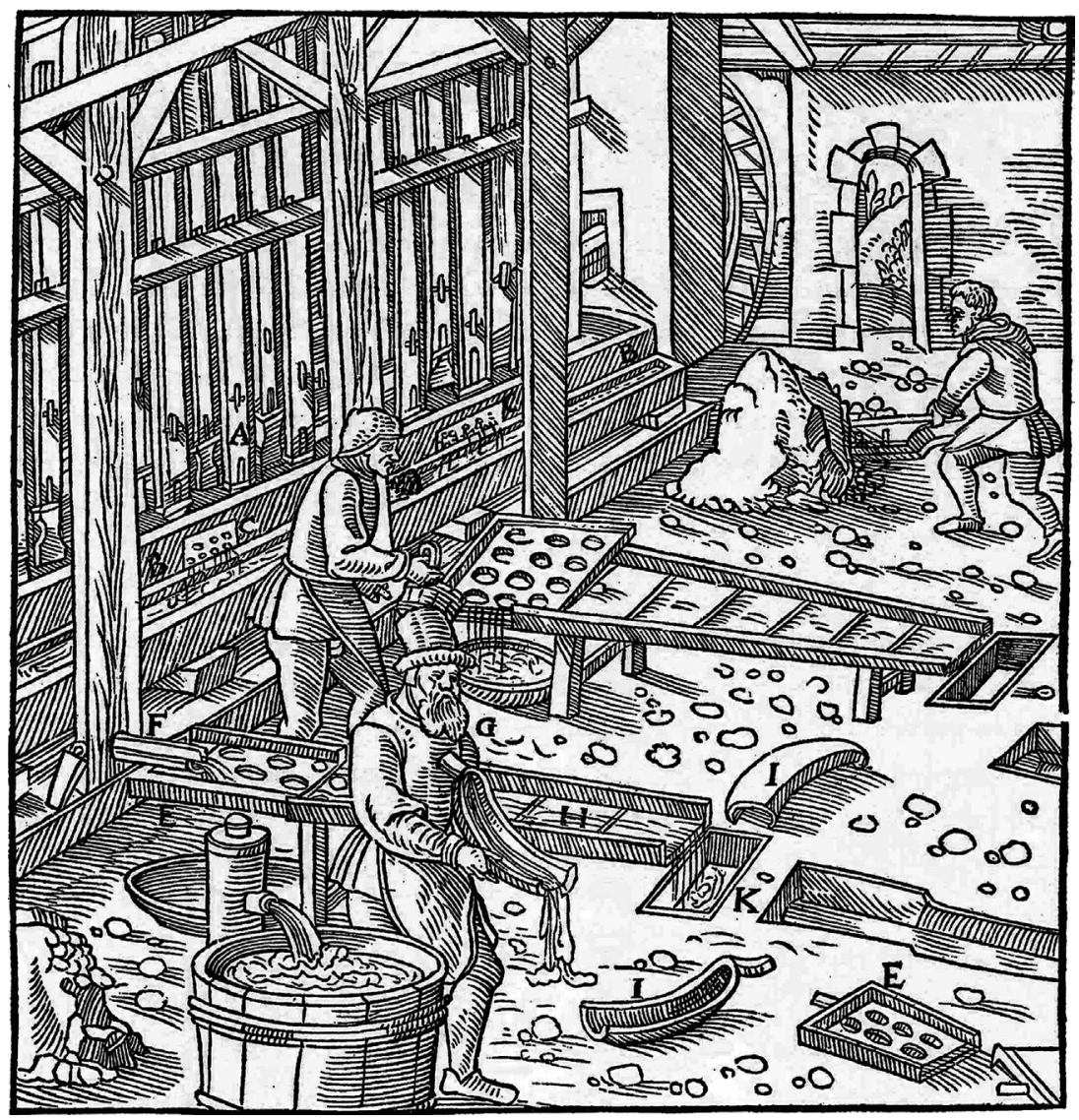

FIG. 16 - G. Agricola, De Re Metallica, 1561, libro VIII, ilustración de un modo de tratar los minerales de oro y de plata en los Alpes Julianos y Réticos y en los Carpatos. Se machacaban en baterías de pilones (A) movidos por un árbol de levas accionado por fuerza hidráulica, en cajas (B) por donde pasaba una corriente que dejaba verter el mineral triturado a través de unos orificios $(C)$ sobre un canal transversal

(D) situado inmediatamente abajo, desde donde caían por un canalillo (F) en unas tablas móviles en cuyo fondo se habian hecho pequeñas cavidades (E). El mineral de dichas cavidades se vertía sobre un recipiente o batea $(G)$ donde se lavaba.

El mineral que superaba las tablas móviles (E) pasaba por otro sector de tablas

(H) con un paño en el fondo donde quedaban retenidas las partículas más finas, que luego eran lavadas en unos recipientes o bateas barquiformes (I).

El estéril caía sobre un canal de evacuación dotado de una primera pileta de decantación (K) de donde se podría recuperar todavía algún mineral muy fino. 


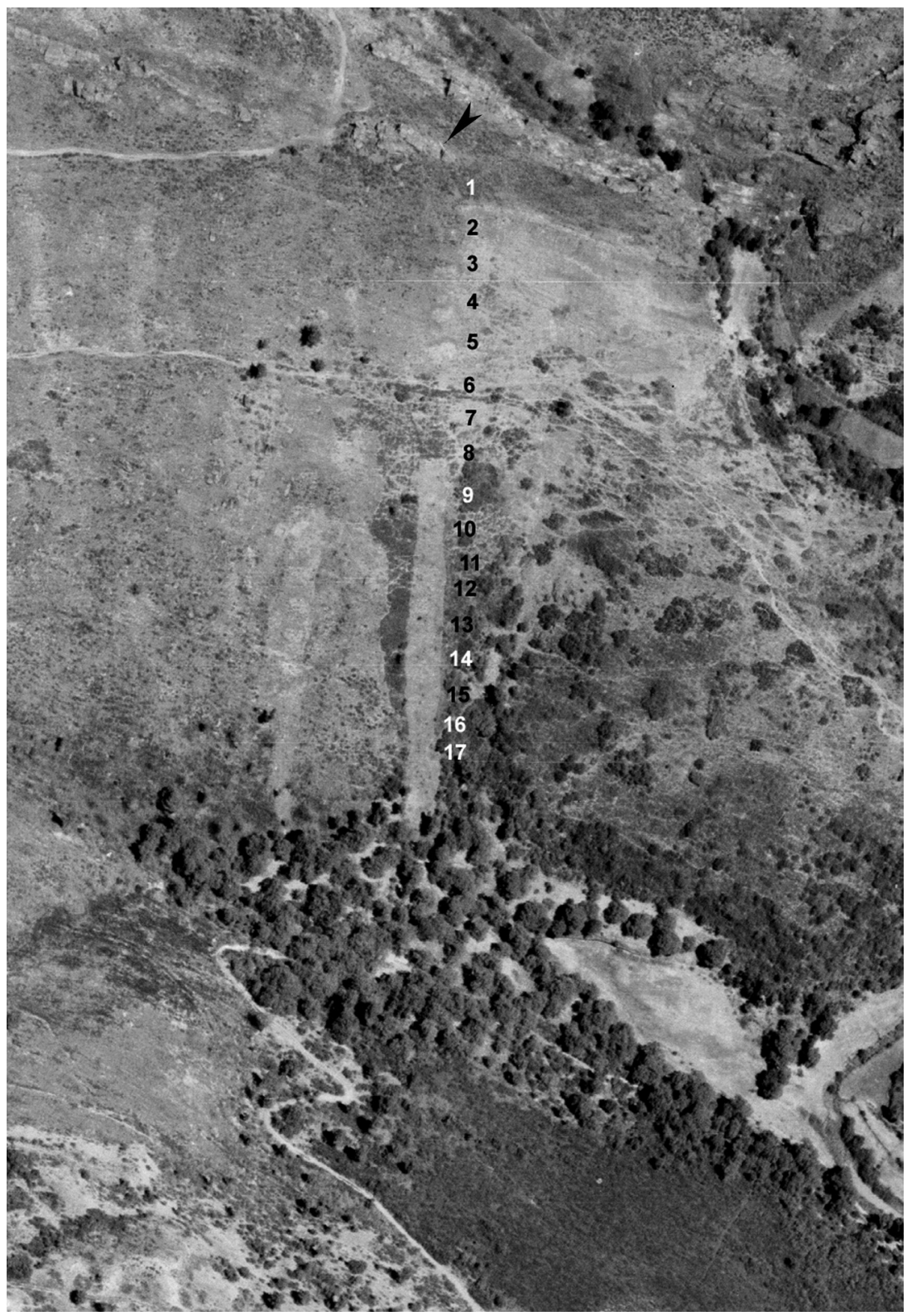

FIG. 17 - Fotografía aérea del vuelo de 1993, E:22.000 (fotograma 001215)

del sector de Fragas das Covas donde se aprecian las series de depósitos escalonados.

Se numera la alineación más oriental. La flecha indica el corte en la roca para dar paso al canal c-2. 


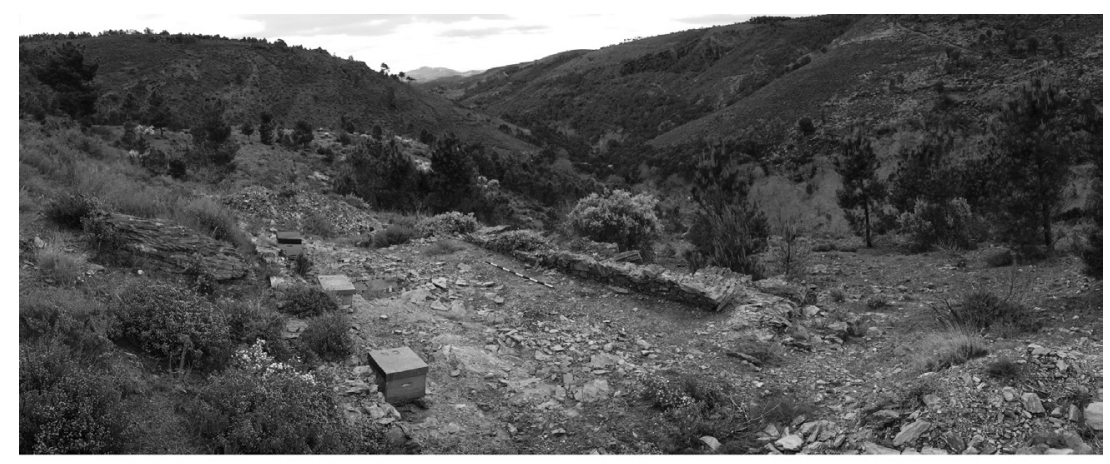

FIG. 18 - Fragas das Covas. Depósito escalonado $n^{\circ} 8$ (serie oriental), vista desde el noroeste (FoTO: JSP).

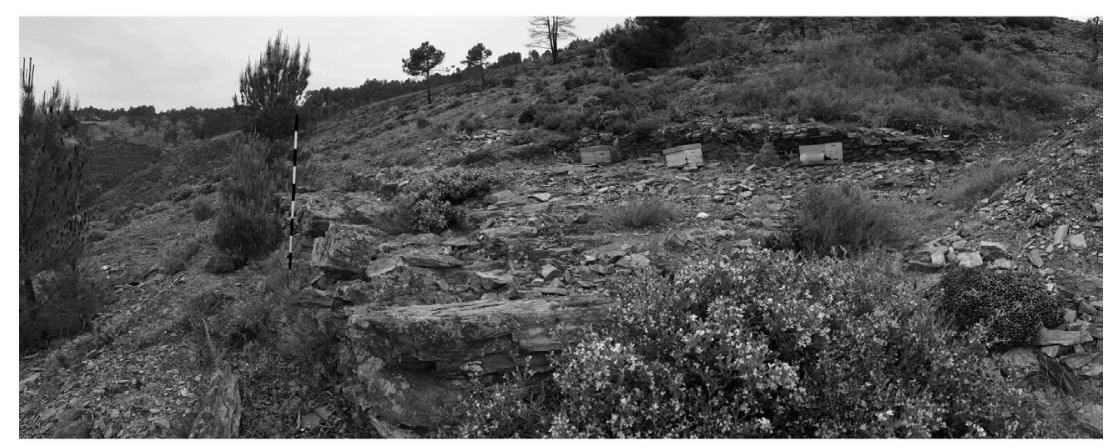

FIg. 19 - Fragas das Covas. Depósito escalonado $n^{\circ} 8$ (serie oriental), vista desde el sureste (Fото: JSP).

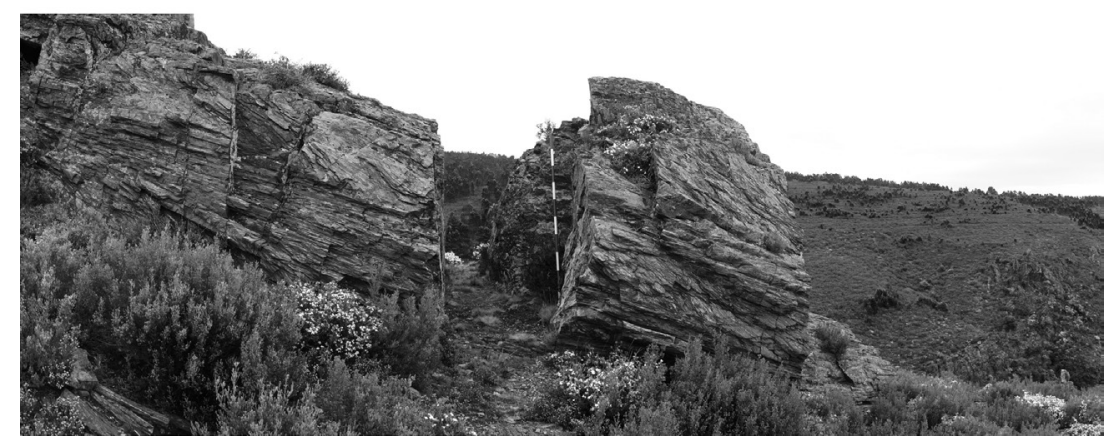

Fig. 20 - Fragas das Covas. Detalle del corte en la roca realizado para dar paso al canal de abastecimiento c-2 (Foто: JSP). 


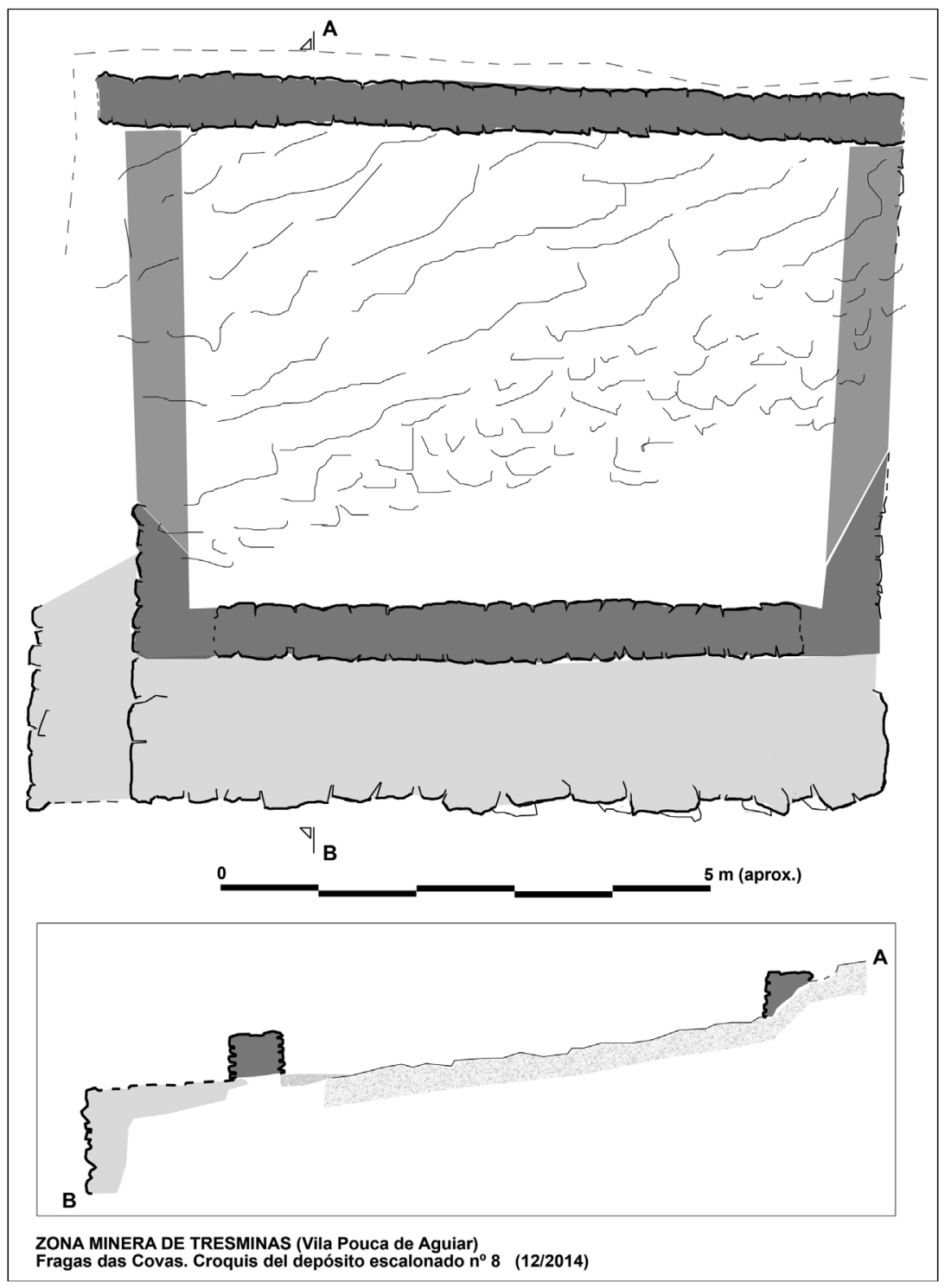

FIG. 21 - Croquis de la planta y sección del depósito escalonado $n^{\circ} 8$ (serie oriental) (JSP). 